\title{
Coxsackie and adenovirus receptor (CAR) is a product of Sertoli and germ cells in rat testes which is localized at the Sertoli-Sertoli and Sertoli-germ cell interface
}

\author{
Claire Q.F. Wang ${ }^{a}$, Dolores D. Mruk ${ }^{a}$, Will M. Lee ${ }^{b}$, C. Yan Cheng ${ }^{a, *}$ \\ ${ }^{a}$ Center for Biomedical Research, The Population Council, 1230 York Avenue, New York, NY 10021, USA \\ ${ }^{\mathrm{b}}$ Department of Zoology, University of Hong Kong, Hong Kong, China
}

\section{A R T I C L E I N F O R M A T I O N}

Article Chronology:

Received 30 August 2006

Revised version received

26 December 2006

Accepted 23 January 2007

Keywords:

Testis

Spermatogenesis

Sertoli-germ cell interaction

Blood-testis barrier

Tight junction

Adherens junction

Ectoplasmic specialization

\begin{abstract}
A B S T R A C T
The coxsackie and adenovirus receptor (CAR), a putative cell-cell adhesion molecule, has attracted wide interest due to its importance in viral pathogenesis and in mediating adenoviral gene delivery. However, the distribution pattern and physiological function of CAR in the testis is still not clear. Here, we identified CAR in Sertoli cells and germ cells of rats. In vivo studies have shown that CAR resides at the blood-testis barrier as well as at the ectoplasmic specialization. The persistent expression of CAR in rat testes from neonatal period throughout adulthood implicates its role in spermatogenesis. Using primary Sertoli cell cultures, we observed a significant induction of CAR during the formation of Sertoli cell epithelium. Furthermore, CAR was seen to be concentrated at inter-Sertoli cell junctions, co-localizing with tight junction protein marker ZO-1 and adherens junction protein N-cadherin. CAR was also found to be associated with proteins of Src kinase family and its protein level declined after TNF $\alpha$ treatment in Sertoli cell cultures. Immunofluorescent staining of isolated germ cells has revealed the presence of CAR on spermatogonia, spermatocytes, round spermatids and elongate spermatids. Taken together, we propose that CAR functions as an adhesion molecule in maintaining the inter-Sertoli cell junctions at the basal compartment of the seminiferous epithelium. In addition, CAR may confer adhesion between Sertoli and germ cells at the Sertoli-germ cell interface. It is possible that the receptor utilized by viral pathogens to breakthrough the epithelial barrier was also employed by developing germ cells to migrate through the inter-Sertoli cell junctions.
\end{abstract}

(c) 2007 Published by Elsevier Inc.

\section{Introduction}

CAR is a $46-\mathrm{kDa}$ transmembrane protein that enables viral attachment and entry into cells for coxsackie virus group B and adenovirus groups 2 and 5 [1]. The availability of CAR on cell surface is a determining factor of a cell's susceptibility to 54 adenoviral vectors for gene delivery [2]. Therefore, extensive 55 studies have been carried out to establish the expression 56 profile of CAR in a variety of human tissues that are of interest 57 to gene therapy, such as brain, heart and muscles [3-6].

\footnotetext{
* Corresponding author. Fax: +1 2123278733.

E-mail address: Y-Cheng@popcbr.rockefeller.edu (C.Y. Cheng).
}

0014-4827/\$ - see front matter @ 2007 Published by Elsevier Inc. doi:10.1016/j.yexcr.2007.01.017 
As a structural component of tight junction and/or adherens junction, CAR is engaged in homotypical trans-interaction at regions of cell-cell contact, promoting cell adhesion and tissue genesis [6-8]. It has been found to associate with scaffolding proteins $\mathrm{ZO}-1$ and $\beta$-catenin $[8,9]$. With two immunoglobulin-like domains in the extracellular region, a single transmembrane domain and a cytoplasmic tail $[1,10]$, CAR joins JAMs and nectins to become a member of the immunoglobulin (Ig) superfamily. Integral transmembrane proteins of Ig superfamily are implicated in cell adhesion and migration. For example, JAM-C was described to promote neutrophil trans-endothelial migration [11], whereas nectinlike molecule- 5 has been shown to enhance cell movement in NIH3T3 cells [12].

In adult rat testes, preleptotene spermatocytes traverse the blood-testis barrier from the basal to the adluminal compartment of the seminiferous epithelium for further development [13]. While they migrate progressively towards the lumen, spermatocytes differentiate into round and elongate spermatids until they detach from the epithelium at stage VIII of the epithelial cycle at spermatogenesis [13]. This movement of germ cells involves rapid disassembly and reassembly of Sertoli-Sertoli and Sertoli-germ cell junctions [14]. Transmembrane proteins at the Sertoli-germ cell interface, for example, cadherins, nectins, integrins and JAMs, function as anchoring devices to maintain attachment between the two types of cells. More importantly, these proteins work in concert to facilitate the movement of germ cells [15]. To date, knockout studies of nectin-2 and JAM-C have yielded mice that were defective in spermatogenesis $[16,17]$, illustrating the essential roles of these adhesion molecules in spermatogenesis.

Due to the structural similarity between CAR, JAMs and nectins, we aimed to investigate the presence of CAR in different cell types of the testis and its physiological significance to spermatogenesis. A recently published study has identified CAR at the acrosome region of mouse and human spermatozoa, as well as its interaction with JAM-C [18]. However, the presence of CAR at the Sertoli-Sertoli cell interface or tight junctions at the blood-testis barrier is not clear, nor do we know for certain about its expression in germ cells during their differentiation in the testis. In this report, we carried out in vivo and in vitro experiments to examine the cellular localization of CAR in Sertoli and developing germ cells, as well as its expression pattern during testicular maturation. In addition, we studied the interaction of CAR with peripheral regulatory proteins and the effects of cytokines treatment (e.g. TNF $\alpha$ ) on its expression level in primary Sertoli cell cultures. These data will help elucidate the physiological role of CAR as a cell adhesion protein in spermatogenesis.

\section{Materials and methods}

\section{Animals}

Male Sprague-Dawley rats were obtained from Charles River Laboratories (Kingston, NY). Rats were sacrificed by $\mathrm{CO}_{2}$ asphyxiation. The use of animals for this study was approved by the Rockefeller University Animal Care and Use Committee with Protocol Numbers 00111, 03017 and 06018.

113

\section{RT-PCR}

Total RNA was extracted from tissues or cells by Trizol Reagent (Invitrogen). About $2 \mu \mathrm{g}$ of total RNA was reverse transcribed into cDNAs using $0.3 \mu \mathrm{g}$ of oligo $(\mathrm{dT})_{15}$ with a Moloney murine leukemia virus reverse transcription kit (Promega) in a final reaction volume of $25 \mu \mathrm{L}$. PCR reaction mixture was composed of $2-3 \mu \mathrm{L}$ of RT product, with $0.4 \mu \mathrm{g}$ of both the sense and anti-sense primers targeted to CAR (see Table 1). Co-amplification of rat ribosomal S16 gene was included to ensure the quality of RT product and the correct composition of each reaction mixture. The cycling parameters used in amplifying CAR are as follows: denaturation at $94{ }^{\circ} \mathrm{C}$ for $1 \mathrm{~min}$, annealing at $58-59{ }^{\circ} \mathrm{C}$ for $1 \mathrm{~min}$, and extension at $72{ }^{\circ} \mathrm{C}$ for $1.5 \mathrm{~min}$, for a total of 26 cycles. After the reaction, $10 \mu \mathrm{L}$ aliquots of PCR product were resolved by $5 \% \mathrm{~T}$ polyacrylamide gels using $0.5 \times$ TBE $(45 \mathrm{mM}$ Tris-borate, 1 mM EDTA, pH 8.0) as a running buffer.

\section{Antibodies}

Primary antibodies purchased from different vendors are listed in Table 2. Each antibody used in this study was shown to cross-react with its corresponding rat protein in our preliminary experiments. Bovine anti-rabbit IgG, bovine anti-goat IgG and goat anti-mouse IgG conjugated to horseradish peroxidase were purchased from Santa Cruz Biotechnology. The rabbit anti-CAR (H300) polyclonal antibody used in this study was raised against amino acid residues $1-300$ mapping the $\mathrm{N}$ terminus of CAR from human origin, which cross-reacted with the rat protein as indicated by the manufacturer. The two predominant isoforms of CAR differ only at the extreme Cterminus of the intracellular tail $[10,19,20]$, therefore the antiCAR (H-300) IgG detected both variants of this protein.

\section{Primary testicular cell cultures}

Sertoli cells

Sertoli cells were isolated from 20-day-old rats as previously described [21]. Freshly isolated cells were cultured at high cell
119 120 121 122 123 124

Table 1 - Primers for RT-PCR analysis of CAR and S16

\begin{tabular}{lllccc} 
Gene & \multicolumn{1}{c}{ Primer sequence } & Orientation & Position & Length (bp) & Reference \\
\hline CAR & 5'-GGAAACTGCCTATCTACCCTGCAA-3' & Sense & $173-196$ & 531 & GenBank Accession \\
& 5'-CTGTAGGTCCAGAATACTCAGAACT-3' & Anti-sense & $678-703$ & Number: NM_053570 \\
S-16 & 5'-TCCGCTGCAGTCCGTTCAAGTCTT-3' & Sense & $15-38$ & 385 & {$[51]$} \\
& 5'-GCCAAACTTCTTGGATTCGCAGCG-3' & Anti-sense & $376-399$ & & \\
\hline
\end{tabular}


Table 2 - Sources of antibodies and their working dilutions used for different experiments in this report

Vendor Antibody against

target protein $^{\mathrm{a}}$

Animal

Catalog

Lot no.

no.

Working

Santa Cruz Biotechnologies

CAR

sc-15405

$\mathrm{J} 1304$

dilution ${ }^{\mathrm{C}}$

(Santa Cruz, CA)

$$
\begin{aligned}
& \text { Rabbit } \\
& \text { Goat } \\
& \text { Mouse, } \\
& \text { Rabbit } \\
& \text { Goat } \\
& \text { Goat } \\
& \text { Goat } \\
& \text { Rabbit } \\
& \text { Rabbit } \\
& \text { Rabbit } \\
& \text { Rabbit } \\
& \text { Goat } \\
& \text { Rabbit } \\
& \text { Mouse, } \\
& \text { Rabbit } \\
& \text { Rabbit } \\
& \text { Rabbit, } \\
& \text { Mouse, } \\
& \text { Mouse, } \\
& \text { Mouse, } \\
& \text { Mouse, } \\
& \text { Rabbit } \\
& \text { Goat } \\
& \text { Goat } \\
& \text { Donkey } \\
& \text { Donkey } \\
& \text { Donkey }
\end{aligned}
$$

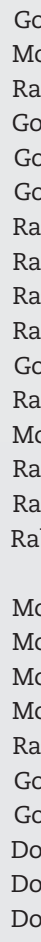

a All primary antibodies used in this report were polyclonal an ng rat proteins.

IB: immunoblotting; IF, immunofluorescent microscopy; IHC, immunohistochemistry; IP, immunoprecipitation.

c Working dilution of primary antibodies was prepared in $\sim 30 \mathrm{ml}$ of PBS-Tris. For all IP experiments, $2 \mu \mathrm{g}$ IgG for each antibody against its corresponding target protein was used per reaction tube.

density $\left(0.5 \times 10^{6}\right.$ cells $\left./ \mathrm{cm}^{2}\right)$ on Matrigel (BD Biosciences)coated 12-well dishes (effective surface area, $3.83 \mathrm{~cm}^{2}$ per well; containing $3 \mathrm{~mL}$ medium, with $\sim 2 \times 10^{6}$ Sertoli cells). Serum-free Ham's F12 nutrient mixture and Dulbecco's modified Eagle's medium (F12/DMEM, 1:1, vol./vol.) was supplemented with gentamicin $(20 \mathrm{mg} / \mathrm{L}), 15 \mathrm{mM}$ HEPES, sodium bicarbonate $(1.2 \mathrm{~g} / \mathrm{L})$, bovine insulin $(10 \mu \mathrm{g} / \mathrm{mL})$, human transferrin $(5 \mu \mathrm{g} / \mathrm{mL})$, epidermal growth factor $(2.5 \mathrm{ng} / \mathrm{mL})$ and bacitracin $(5 \mu \mathrm{g} / \mathrm{mL})$. Cultures were designated as "time 0" at the time of plating. Cells were then incubated at $35^{\circ} \mathrm{C}$ in a humidified atmosphere of $95 \%$ air $-5 \% \mathrm{CO}_{2}$. To obtain Sertoli cell cultures with purity greater than $98 \%$, cells were hypotonically treated $36 \mathrm{~h}$ after plating with $20 \mathrm{mM}$ Tris (pH 7.4), for $2.5 \mathrm{~min}$ at $22^{\circ} \mathrm{C}$ to lyse contaminating germ cells [22]. The wells were then washed twice with F12/DMEM, media were replaced every $24 \mathrm{~h}$, and cells were incubated for an additional 5-7 days [23], however, it is noted that functional tight and anchoring junctions were established within 23 days after cell plating (see below) [23]. To terminate cultures at specified time points, cells were rinsed with cold PBS once and then scraped from the wells with lysis buffer for protein lysate preparation. For immunofluorescent staining, Sertoli cells were cultured at low density $\left(0.1 \times 10^{6} \mathrm{cells} / \mathrm{cm}^{2}\right)$ to 175 allow the formation of a confluent monolayer with tight 176 junction and anchoring junctions. Cells plated at higher 177 densities often grow into an epithelium with overlapping cell 178 layers, which would later become an obstacle for imaging 179 cell borders.

\section{Germ cells}

Germ cells were isolated from 90-day-old rats by a mechanical procedure without the use of trypsin as previously described [24]. Since the glass wool filtration step was omitted from the isolation procedures, germ cell preparation for this study contained elongating/elongated spermatids. The ratio of spermatogonia:spermatocytes: round spermatids: elongating/elongate spermatids was similar to that of germ cells in vivo when assessed by DNA flow cytometry [24]. Germ cells were used immediately after isolation.

Sertoli cells and germ cells isolated with the above described protocol contained negligible contamination of other type of cells, which was verified by RT-PCR and immunoblotting analysis of cell-type specific protein markers [25]. For example, c-kit receptor was amplified by RT- 
196 PCR and probed in immunoblot to detect possible germ cell 197 contamination. Likewise, testin, 3 $\beta$-hydrosteroid dehydro198 genase, and fibronectin were used to monitor the presence 199 of contaminating Sertoli cells, Leydig cells and peritubular 200 myoid cells, respectively [25].

\section{Transepithelial electrical resistance (TER)}

202 The establishment of tight junction permeability barrier was 203 assessed by quantifying the TER across the cell epithelium as described [26]. In brief, Sertoli cells were isolated from 20-day- 204 old rats and seeded at a cell density of $0.75 \times 10^{6} \mathrm{cells} / \mathrm{cm}^{2}$. Such 205 density is required for TER studies, because low-density cell 206 cultures would generate small blank areas with no or very few 207 cells on the bicameral units, forming leaky spots for electric 208 current to pass through. This renders TER measurement 209 inaccurate or impossible. Cells were plated onto the bicameral 210 units with F12/DMEM medium in each of the apical and basal 211 chambers. The assembly of inter-Sertoli tight junctions was 212 assessed by TER across the Sertoli cell epithelia using a 213

A

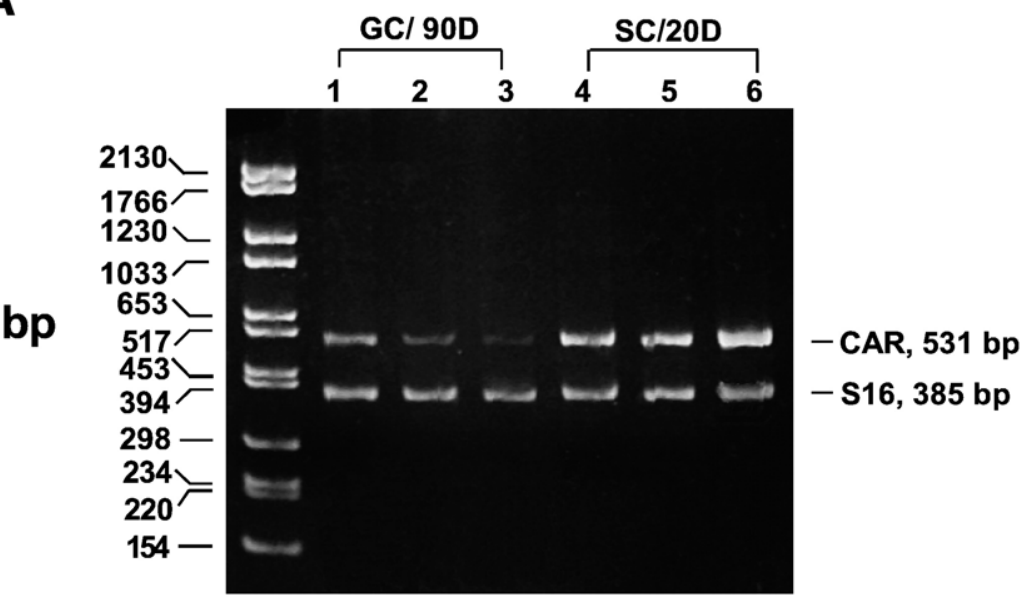

B

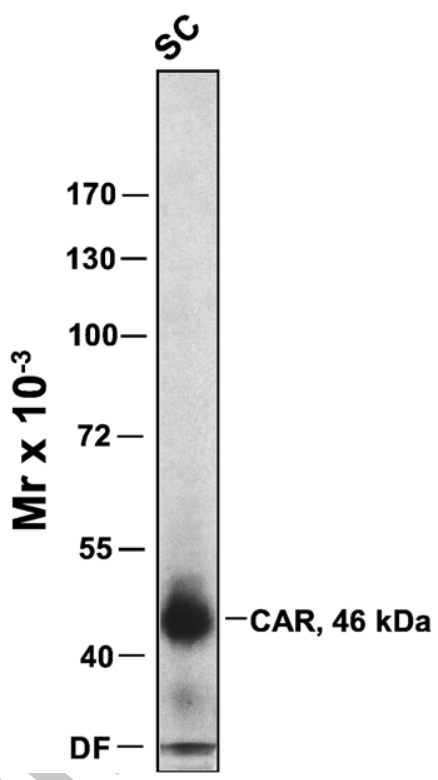

C

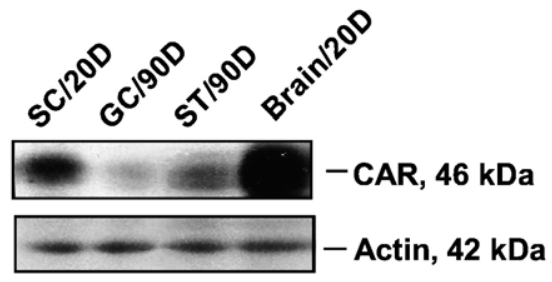

D

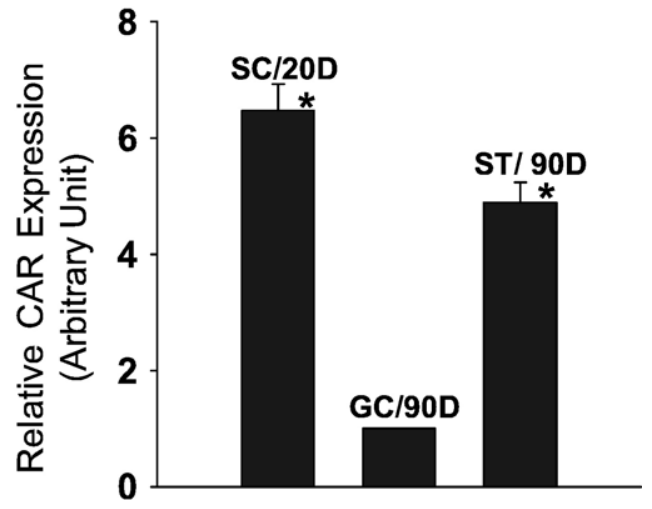

Fig. 1 - Expression of CAR in Sertoli and germ cells. (A) Results of RT-PCR using total RNA isolated from Sertoli (SC) and germ cells (GC) to assess the steady-state mRNA level of CAR. DNA size marker is on the left (bp, base pair). Each lane represents Sertoli cell or germ cell RNA extracted from a separate batch of cells. D, day. (B) A single prominent band corresponding to the apparent $\mathrm{Mr}$ of CAR at $46 \mathrm{kDa}$ was detected on the immunoblot using Sertoli cell lysate (100 $\mu \mathrm{g}$ protein), illustrating the specificity of this antibody. DF, dye-front. (C) Protein extracts of Sertoli cells (from 20-day-old rats), germ cells (from 90-day-old rats) and seminiferous tubules (from 90-day-old rats) were analyzed by immunoblotting, using a rabbit anti-CAR (H-300, Santa Cruz) polyclonal antibody. The same blot was probed with $\beta$-actin to confirm equal protein loading. Protein lysate of rat brain (from 20-day-old rats) was loaded onto the same gel, serving as positive control. D, day. (D) Bar graph summarizes results of three sets of immunoblots using different batches of lysates from Sertoli and germ cells and seminiferous tubules (ST). D, day. The level of CAR in germ cells was arbitrarily set at 1 against which 1-way ANOVA was performed. ${ }^{*} P<0.01$. 
214 Millicell (Millipore Corp) electrical resistance system. Briefly, 215 current was passed through the epithelial monolayer between 216 two silver-silver chloride electrodes. Resistance was calcu217 lated from the change in ohm $(\Omega)$ across the monolayer induced by a short ( $\sim 2$ s) $20-\mu \mathrm{A}$ pulse of current. The 218 resistance was multiplied by the surface area of the filter to 219 yield the area resistance in $\Omega \mathrm{cm}^{2}$. The net value of electrical 220 resistance was then computed by subtracting the background, 221
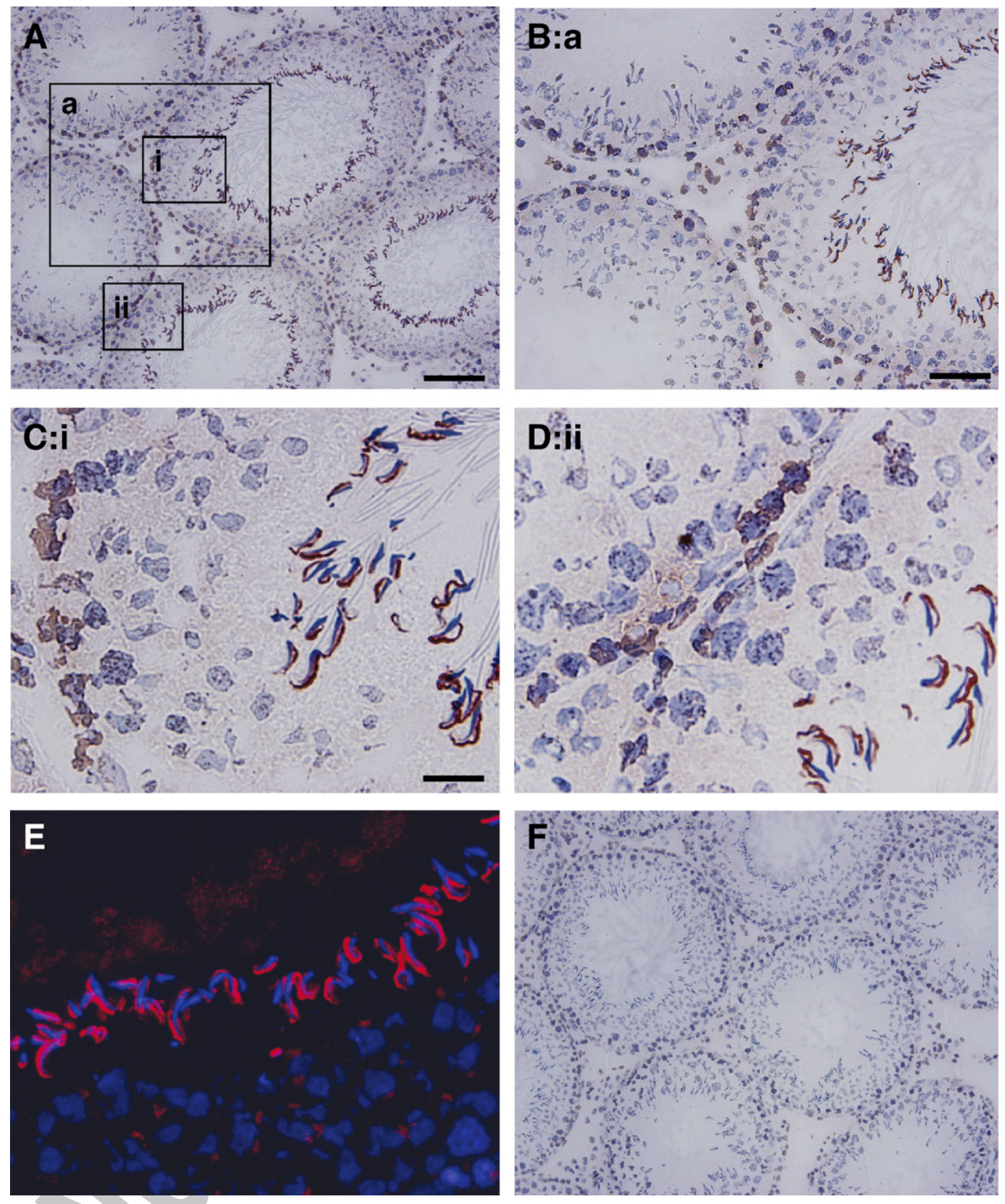

Fig. 2 - Localization of CAR in the seminiferous epithelium of adult rat testes by immunohistochemistry. (A) Frozen sections of adult rat testes were stained using a rabbit anti-CAR polyclonal antibody. Signal was detected at the basal compartment of the epithelium in virtually all stages of the epithelial cycle. However, strongest staining was found at the apical ectoplasmic specialization in stage VIII tubules. (B) Magnified view of the boxed area " $a$ " in A, showing CAR staining at the basal compartment, which is consistent with its localization at the blood-testis barrier. (C-D) Corresponding to boxed area (i) and (ii). Sickle-shaped CAR staining was concentrated at site of apical ES in stage VIII seminiferous tubules, where elongated spermatids anchor onto Sertoli cells in the epithelium. CAR staining was also found at the site of blood-testis barrier. (E) Localization of CAR by immunofluorescent staining. Sections were incubated with a rabbit anti-CAR, to be followed by a donkey anti-rabbit IgG-Cy3 conjugate. Cell nuclei were visualized by DAPI staining. Merged image of CAR and DAPI staining identified CAR at the apical and round spermatids. (F) Control experiment in which testis sections were stained with normal rabbit IgG at the same dilution as the primary antibody shown in A-E. Scale bar $=100 \mu \mathrm{m}$ in A, which also applies to F. Scale bar $=50 \mu \mathrm{m}$ in $\mathrm{B}$. Scale bar $=15 \mu \mathrm{m}$ in $\mathrm{C}$, which also applies to $\mathrm{D}$ and $\mathrm{E}$. 
222 which was measured on Matrigel-coated cell-free bicameral 223 units, from values of Sertoli cell-plated chambers [26]. Under 224 these conditions, inter-Sertoli tight junctions were mostly 225 formed at $\sim 2-3$ days [23]. Each time point had triplicate 226 cultures, and each experiment was repeated 3 times using 227 different batches of primary Sertoli cell cultures.

\section{Immunofluorescent microscopy}

229 Frozen cross sections of testes $(\sim 6 \mu \mathrm{m})$ obtained in a cryostat 230 were mounted on poly-L-lysine-coated slides, fixed with 231 Bouin's fixative and permeabilized with $0.2 \%$ Triton X-100 232 for $5 \mathrm{~min}$. Sections are then washed with PBS and blocked with $23310 \%$ normal goat or donkey serum for $1 \mathrm{~h}$. This is followed by 234 incubation with primary antibodies overnight at room tem235 perature (see Table 2 for working dilutions). Slides were 236 washed in PBS before incubation with secondary antibodies 237 conjugated with FITC (green) or Cy3 (red). Sections were 238 mounted in Vectashield Hardset with 4',6'-diamino-2-pheny239 lindole (DAPI) (Vector Laboratories, Burlingame, CA). Fluores240 cent micrographs were acquired by using an Olympus BX40 241 microscope (Olympus Corp., Melville, NY) equipped with 242 Olympus UPlanF1 fluorescent optics and an Olympus DP70 $24312.5 \mathrm{MPa}$ digital camera. Sections were also stained with 244 normal rabbit, mouse or goat IgG as negative controls. For cell 245 staining, Sertoli cells were cultured for 2 to 3 days at $2460.1 \times 10^{6}$ cells $/ \mathrm{cm}^{2}$ on Lab-Tek ${ }^{\circledR}$ Chamber Slide ${ }^{\mathrm{TM}}$ Systems 247 (Nalgene Nunc International) before fixation with Bouin's 248 solution and immunofluorescent microscopy was performed 249 as detailed above. To eliminate inter-experimental variations, 250 all samples within an experimental group were processed 251 simultaneously by mounting $2-3$ cross sections per slide. 252 Several slides were processed in parallel. Immunohistochem253 istry studies were handled with the same practice.

\section{Immunohistochemistry}

255 Immunohistochemistry was performed with a Histostain-SP'M 256 kit (Zymed, CA). Frozen sections of $(\sim 6 \mu \mathrm{m})$ of testes were mounted onto poly-L-lysine-coated slides and fixed in Bouin's fixative. Sections were treated with $3 \% \mathrm{H}_{2} \mathrm{O}_{2}$ in methanol (vol./ vol.) to block the endogenous peroxidase activity, to be followed by incubation with $10 \%$ normal goat serum to block nonspecific binding. Thereafter, sections were incubated with a rabbit-anti-CAR (Santa Cruz, CA; dilution 1:100) polyclonal antibody in a moist chamber at room temperature overnight. Sections were then incubated in biotinylated secondary antibody for $30 \mathrm{~min}$ and treated with streptavidin peroxidase for approximately $5 \mathrm{~min}$. Immunoreactive CAR appeared as reddish-brown precipitates on the sections. Slides were then counterstained with hematoxylin and mounted in glycerol vinyl alcohol (GVA, Zymed). Negative controls were included by incubating the sections with normal rabbit IgG at the same dilution as the primary antibody. Micrographs reported herein were representative results from 3 to 6 experiments using different samples.

\section{Immunoblot analysis}

Testes or cell lysates were prepared in immunoprecipitation buffer [50 mM Tris, $150 \mathrm{mM} \mathrm{NaCl}, 1 \%$ Nonidet P-40 (vol./vol.), $2 \mathrm{mM}$ EGTA, $1 \mathrm{mM}$ PMSF, $1 \mathrm{mM}$ sodium orthovanadate, $2 \mathrm{mM}$ $\mathrm{N}$-ethylmaleimide, $10 \%$ glycerol (vol./vol.), pH 7.4 at $\left.22{ }^{\circ} \mathrm{C}\right]$. An equal amount of proteins from lysates $(\sim 100 \mu \mathrm{g})$ was resolved by SDS-PAGE (7.5-14\% T SDS polyacrylamide gels) under reducing conditions. All samples within an experimental group were processed simultaneously to eliminate inter-experimental variations. Proteins were transferred onto nitrocellulose membranes and probed with primary antibodies listed in Table 2. The blots were developed with an enhanced chemiluminescence system using kits from Amersham Pharmacia Biotech (Piscataway, NJ). Each immunoblot experiment was repeated at least three times using different sets of samples to obtain sufficient data for statistical analysis. In selected experiments, immunoblots were probed with a different antibody, namely the mouse anti-CAR antibody instead of the rabbit antibody (see Table 2), which yielded virtually identical results.

Fig. 3 - Changes in CAR expression in rat testes during testicular maturation. (A) Immunofluorescent staining of CAR (H-300) was performed on frozen sections of rat testes of different ages: 15- (a-d), 25- (e-h), and 60-day-old rats (i-l) vs. adult rat kidney (body weight, $300 \mathrm{~g}$ ) (m-p). A mouse antibody against ZO-1 conjugated with FITC (green fluorescence) was used to localize the blood-testis barrier. Sections were then incubated with a donkey anti-rabbit Cy3-conjugated antibody to visualize CAR (red fluorescence). (m-p): Cross-section of frozen rat kidney was included to demonstrate the specificity of CAR staining. Signals of CAR staining co-localized with ZO-1 to tight junctions in the collecting tubules of rat kidney. At 15 days, when blood-testis barrier was absent and only spermatogonia were found in the seminiferous tubules, CAR staining was detected at the Sertoli-Sertoli and Sertoli-germ cell interface, surrounding cell nuclei. At day 25, CAR staining was observed to be co-localizing with ZO-1 to the newly formed blood-testis barrier, along with staining surrounding the acrosome region of late round spermatids. At day 60 , when the rat testis matured with complete cycles of spermatogenesis, CAR staining were found at germ cells of all stages, yet the signals were most intense in early stage VIII tubules, where elongated spermatids anchor their heads to Sertoli cells in the epithelium. Signals were also detected at the blood-testis barrier, but not of the same intensity compared to those at the apical ectoplasmic specialization. Scale bar $=25 \mu \mathrm{m}$ in (a), which also applies to (b-d) and ( $\mathrm{m}-\mathrm{p})$. Scale bar $=50 \mu \mathrm{m}$ in (e), which also applies to (f-l). (B) Immunohistochemical localization of CAR in the seminiferous epithelium was performed on

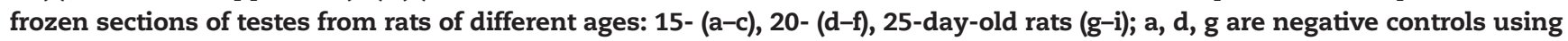
normal rabbit IgG for each sample group. Scale bar $=50 \mu \mathrm{m}$ in (b), which also applies to (e, h) and upper-right corner of (a, $d, g)$. Scale bar $=25 \mu \mathrm{m}$ in (a), which also applies to (c, d, f, g, i). (C) Immunoblot of CAR using testis lysates from rats of different ages. Brain lysate of 20-day-old rats served as a positive control. Bar graph summarizes results of three sets of immunoblots using separate batches of testis lysate preparation. The level of CAR in testes from 90-day-old rats was arbitrarily set at 1. (For interpretation of the references to colour in this figure legend, the reader is referred to the web version of this article.) 


\section{Immunoprecipitation (IP)}

About $400 \mu \mathrm{g}$ of proteins from testis or Sertoli cell lysates were used for IP. Sertoli cells were cultured alone for 4 days at $0.5 \times 10^{6} \mathrm{cells} / \mathrm{cm}^{2}$ on Matrigel-coated dishes with established functional tight and anchoring junctions that mimicked the in vivo cellular physiology and morphology as earlier reported [23] prior to their used for lysate preparation. Testis or Sertoli cell lysates were first pretreated with $2 \mu \mathrm{g}$ of rabbit or mouse IgG for approximately $1 \mathrm{~h}$, followed by incubation with $10 \mu \mathrm{L}$ Protein $\mathrm{A} /$ G-PLUS agarose (Santa Cruz, CA) for $2 \mathrm{~h}$ to eliminate nonspecific binding of protein with IgG or agarose. After spinning down the agarose beads, supernatants were collected into new tubes for IP. $2 \mu \mathrm{g}$ of primary antibody was added to this supernatant and incubated overnight. In negative controls, mouse or rabbit IgG of equivalent amount were applied in substitute of primary antibodies. The immunocomplexes were then precipitated by incubating with $20 \mu \mathrm{L}$ of Protein A/G PlusAgarose for approximately $6 \mathrm{~h}$. After that, the immunocomplexes were washed four times with $300 \mu \mathrm{L}$ washing buffer [50 mM Tris-HCl, $150 \mathrm{mM} \mathrm{NaCl}, 1 \%$ Nonidet P-40 (vol./vol.), $1 \mathrm{mM}$ EGTA, $1 \mathrm{mM}$ PMSF, pH 7.4 at $22^{\circ} \mathrm{C}$ ] by gentle resuspension and mild centrifugation (5 min, 1000×g). Precipitated immunocomplexes were released from agarose beads by heating at $100{ }^{\circ} \mathrm{C}$ for $10 \mathrm{~min}$ in SDS-sample buffer [0.125 M Tris, pH 6.8 at $22{ }^{\circ} \mathrm{C}$, containing 1\% SDS (wt./vol.), 1.6\% 2mercaptoethanol (vol./vol.), and $20 \%$ glycerol (vol./vol.)] for $10 \mathrm{~min}$. Proteins were then resolved by SDS-PAGE, and immunoblotting was performed as described in the previous section. Lysates from normal rat testes or Sertoli cells were used to serve as positive controls. We opted to use Sertoli cell lysates for co-IP instead of testis lysates for data reported
309

A

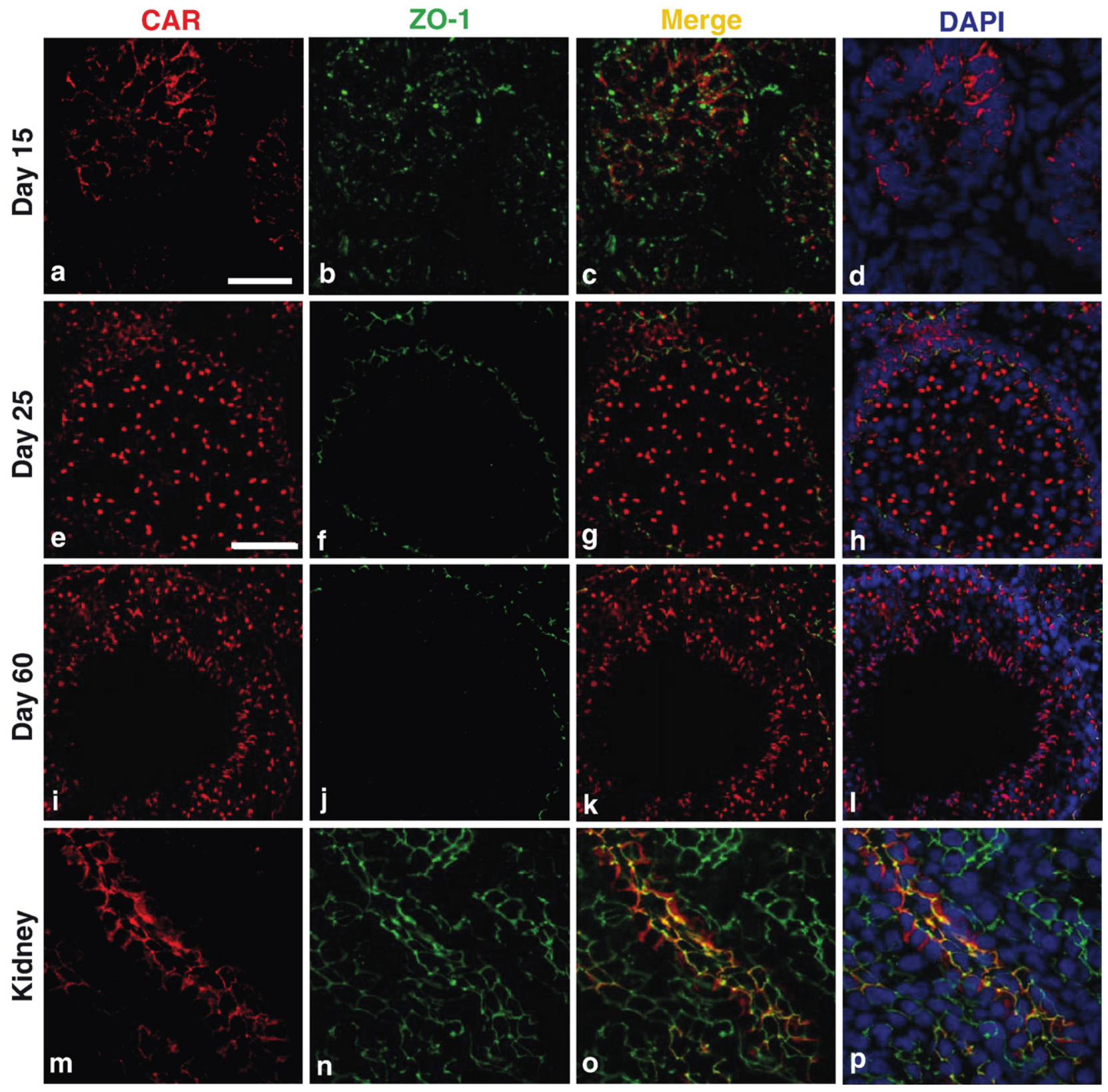

Please cite this article as: C.Q.F. Wang, et al., Coxsackie and adenovirus receptor (CAR) is a product of Sertoli and germ cells in rat testes which is localized at the Sertoli-Sertoli and Sertoli-germ..., Exp. Cell Res. (2007), doi:10.1016/j.yexcr.2007.01.017 
B
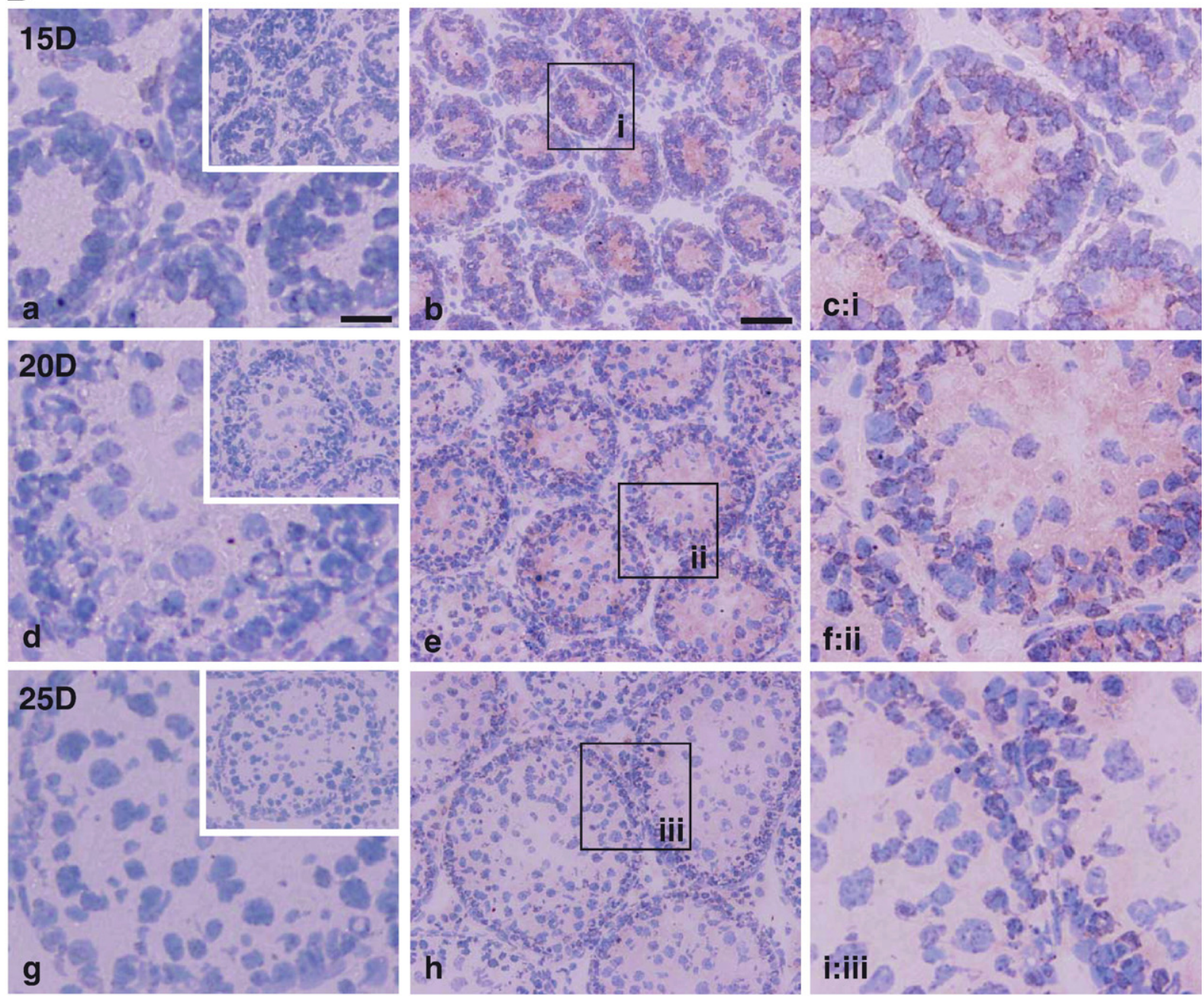

\section{C a}

Age of Rats (Testes Lysates)
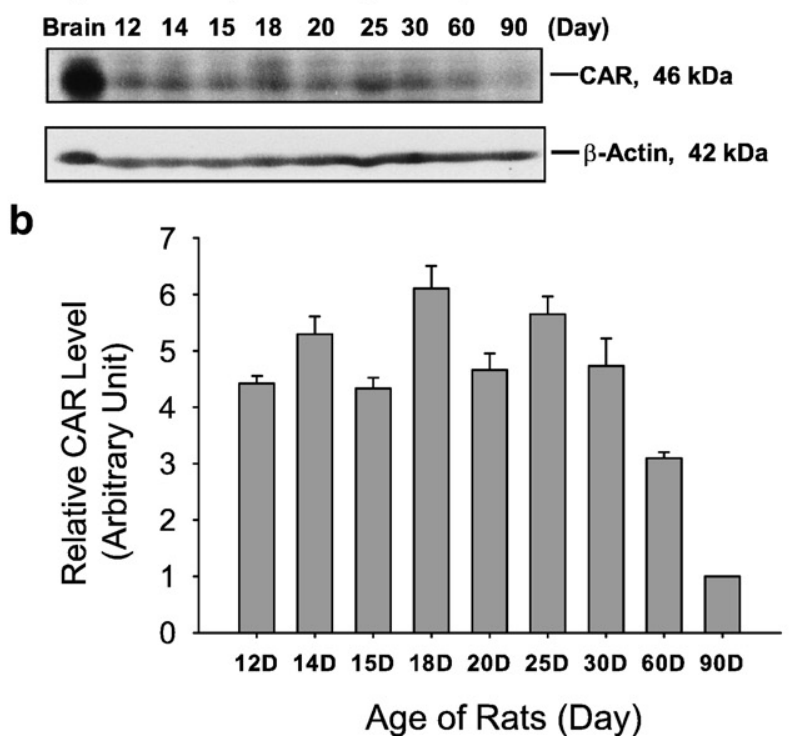

Fig. 3 (continued).

Please cite this article as: C.Q.F. Wang, et al., Coxsackie and adenovirus receptor (CAR) is a product of Sertoli and germ cells in rat testes which is localized at the Sertoli-Sertoli and Sertoli-germ..., Exp. Cell Res. (2007), doi:10.1016/j.yexcr.2007.01.017 
A
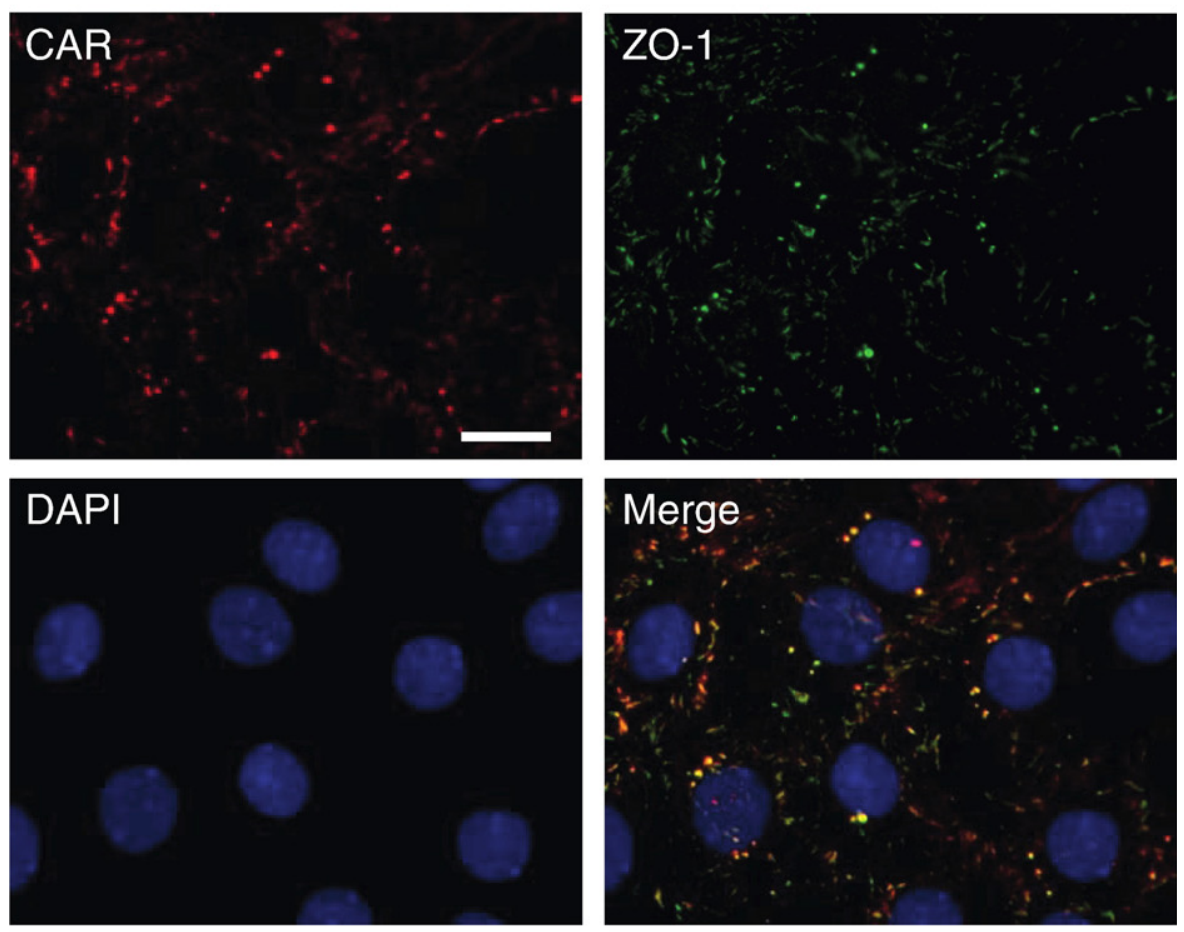

B
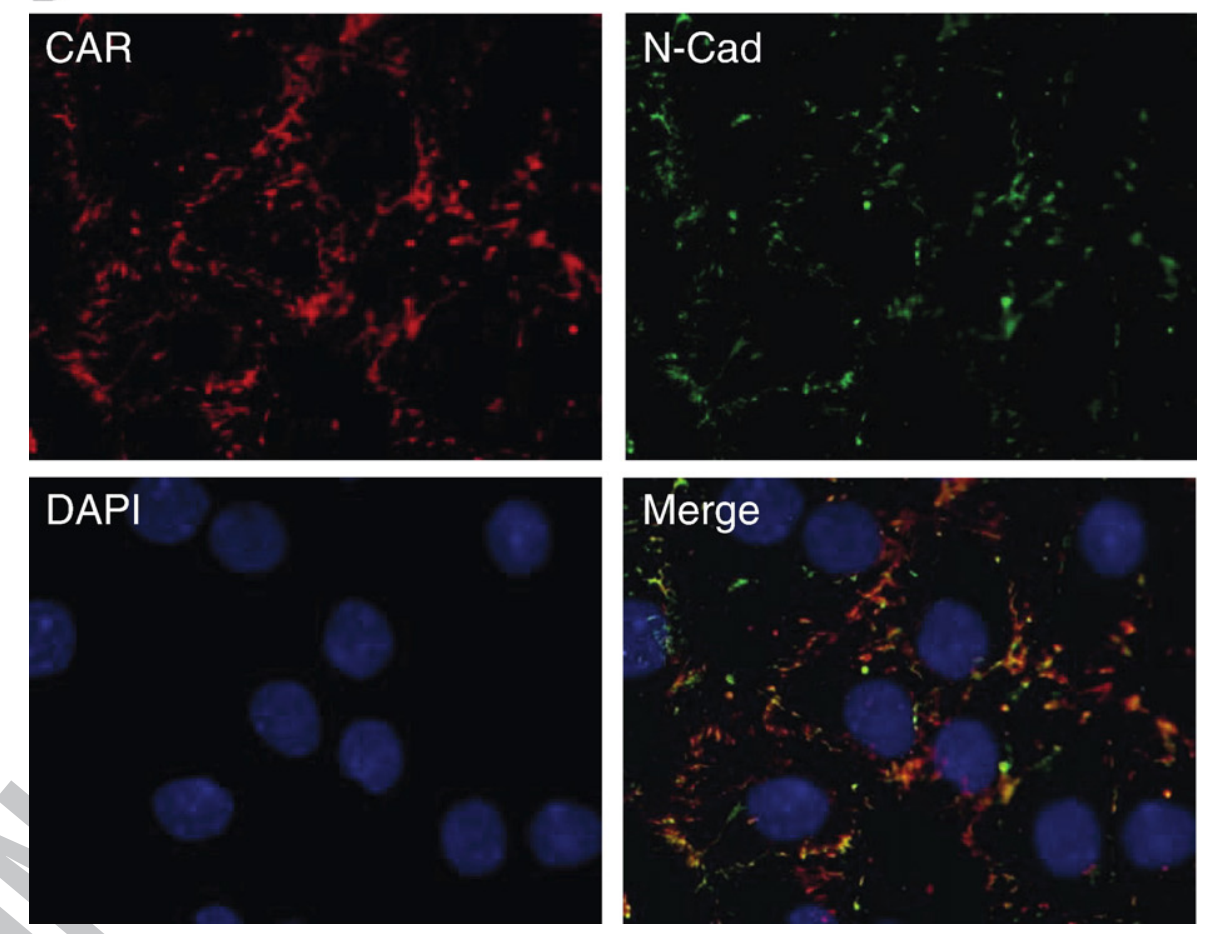

Fig. 4 - CAR localize at cell-cell contacts of Sertoli cells. Sertoli cells were cultured at low density $\left(1 \times 10^{5} \mathrm{cells} / \mathrm{cm}^{2}\right)$ for 3 days before staining. Areas of co-localization appear as orange. Immunofluorescent micrograph demonstrates that CAR was heavily concentrated at inter-Sertoli tight junctions, though staining occasionally was also seen close to the nucleus. (A) Cells were incubated with a rabbit anti-CAR polyclonal IgG as primary antibody, followed by a goat anti-rabbit CY3-conjugated secondary antibody. A mouse anti-ZO-1 FITC conjugate was used to locate inter-Sertoli tight junctions. (B) Cells were incubated with a rabbit anti-CAR (H-300) polyclonal antibody, along with a mouse anti-N-cadherin monoclonal antibody. $\mathrm{N}$-Cadherin is a known component of the inter-Sertoli cell junctions at the blood-testis barrier. Scale bar $=20 \mu \mathrm{m}$ in A, which also applies to B. This experiment was repeated at least 4 times over a period of 18 months using different batches of Sertoli cells where cultures were terminated on either day $2(n=2)$ or day $3(n=2)$, and similar results were obtained for all experiments. (For interpretation of the references to colour in this figure legend, the reader is referred to the web version of this article.) 
325 herein to avoid results of protein-protein association between 326 CAR and other peripheral proteins that were derived from cells 327 in the interstitium (e.g., Leydig cells, macrophages, endothelial 328 cells in microvessels) and the tunica propria (e.g., peritubular 329 myoid cells, lymphatic cells).

\section{Statistical analysis}

331 Statistical analysis was performed using one-way ANOVA 332 using the GB-STAT Statistical Analysis Software package 333 (Version 7.0, Dynamic Microsystems, Inc., Silver Spring, MD).

\section{Results}

\section{CAR is a product of both Sertoli and germ cells in rat testes}

In order to examine the presence of CAR in normal rat testes, we performed RT-PCR with total RNA extracted from Sertoli cells and germ cells. These cell preparations were contaminated with a negligible number of other cells as described in Materials and methods. S16 was co-amplified in all experiments to confirm the correct composition of each reaction mixture and the quality of mRNA. As the two isoforms of CAR vary only at the cytoplasmic C-terminus, we designed a pair of primers that flanked a large region in the extracellular domain. As shown in Fig. 1A, sharp bands of expected size (531 bp) were detected in both Sertoli and germ cells. This PCR product was confirmed by direct nucleotide sequencing at Genewiz (North Brunswick, NJ). Each of the three lanes of Sertoli and germ cells in Fig. 1A represents RNA sample prepared from separate batches of cells.

To test whether CAR is translated into a functional protein in the testis, we carried out immunoblot analysis. As CAR is most abundantly expressed in rat brains at the early development stage [7], brain lysate from 20-day-old rats was included as a positive control. When the immunoblot of Sertoli cell lysate was probed with a rabbit anti-CAR (H-300) polyclonal antibody, only one single prominent band was detected at $46 \mathrm{kDa}$ (Fig. 1B), illustrating the specificity of the antibody. We also examined the expression level of CAR in different cellular fractions of the testis as shown in Fig. 1C. In comparison to germ cells, Sertoli cells expressed a much higher level of CAR, which contributed substantially to the amount of CAR protein detected in lysates of rat seminiferous tubules. Fig. 1D is a histogram representing densitometrically scanned results of Fig. 1C, showing that the abundance of CAR in Sertoli cells is approximately 6 times that of germ cells.

Localization of CAR in the seminiferous epithelium of adult rat testes

Immunohistochemistry was used to examine the distribution pattern of CAR in adult rat testes (Fig. 2A). Fig. 2B is a magnified view of boxed area (a) in Fig. 2A, whereas Figs. $2 \mathrm{C}$ and $\mathrm{D}$ correspond to boxed area (i) and (ii), respectively. CAR was seen to be concentrated at the sites of apical ectoplasmic specialization of stage VIII seminiferous tubules, where elongated spermatids anchor onto Sertoli cells before spermatogenesis.

Immunoreactive signals were discernible on round spermatids and early elongating spermatids as well, but the most intense reddish-brown precipitates were localized to the convex side of elongate spermatid heads (Figs. 2C and D). This observation is in agreement with a recent report [18], in which signals from immunofluorescent staining of CAR in rat seminiferous tubules were found to be very pronounced in elongate spermatids of stage VIII tubules. More importantly, our data demonstrate that CAR expression was not restricted to germ cells only. Robust signals were also detected along the basal compartment of the seminiferous tubule, especially at the site of the blood-testis barrier. In Figs. $2 \mathrm{C}$ and $\mathrm{D}$, reddish-brown precipitates of CAR were found near the basal lamina of the seminiferous epithelium sitting side by side with sickle shaped CAR staining at elongate spermatids. We also noticed minor staining on Leydig cells, which is consistent with findings of another research group [27]. Immunofluorescent studies (Fig. $2 \mathrm{E})$ yielded similar results, showing the same staining pattern as seen in Figs. 2A-D. Here, CAR signal appears as red, while cell nuclei were stained blue with DAPI. Again, we observed CAR residing at the convex side of elongate spermatid heads. Fig. 2F serves as a negative control where cross-sections of testes were incubated with purified rabbit IgG at the same concentration as that of the primary antibody. No immunoreactivity was noticeable in the negative control, which verifies the specificity of CAR (H-300) antibody. The results reported in Figs. 2A-D by immunohistochemistry were also confirmed using a different anti-CAR antibody raised in a goat (see Supplementary Fig. 1), illustrating the localization of CAR in the seminiferous epithelium as shown in Fig. 2 is specific to CAR.

\section{CAR expression in rat testes changes during development}

The expression of CAR is highly regulated during development. In neonatal rats and mice, CAR was found to be abundant in various tissues (e.g., heart, brain, skeletal muscle), but its protein level would drop rapidly in adult animals $[7,28,29]$. We thus sought to study the expression pattern of CAR during testicular maturation. Immunofluorescent staining was performed on frozen sections of rat testes of different ages. In 15-day-old rats (Figs. 3A, a-d), the bloodtestis barrier has not yet formed, CAR was seen to be surrounding the nuclei of Sertoli cells and spermatogonia at cell-cell interface. Signals of CAR (red) coincided with those of ZO-1 (green) in most areas examined (Figs. 3A, c), suggesting that CAR is implicated in the formation of the blood-testis barrier. In 25-day-old postnatal rats, the blood-testis barrier has already been established, as manifested by localization of ZO-1 near the basal lamina of the seminiferous epithelium (Figs. 3A, e-h). Here, CAR was observed to be associated with spermatogonia, spermatocytes and round spermatids. Of note is that elongating or elongate spermatids were absent in 25day-old rat testes. At the same time, modest CAR staining was also found near the basal lamina of seminiferous tubules, where it co-localized with $\mathrm{ZO}-1$ at the blood-testis barrier (Figs. 3A, e-h). By day 60 postnatal, rats are sexually mature, with full epithelial cycles in the seminiferous tubules and continuous waves of spermatogenesis. In cross sections of adult rat testes, CAR staining appeared to be strongest in stage VIII tubules, at the site of apical ES where elongate spermatids anchor onto to Sertoli cells before spermatogenesis (Figs. 3A, i- 
1). CAR signals also associated with spermatogonia and round spermatids near the basal compartment of the tubules. Distinct fluorescent signals of CAR were also detected at the blood-testis barrier (see Figs. 3A, i, k), which is identified by staining with mouse anti-ZO-1 FITC conjugate (see Figs. 3A, j). CAR and ZO-1 fluorescent signals were also co-localized in the seminiferous epithelium near the basement of the seminiferous tubules, consistent with their localization at the bloodtestis barrier (Figs. 3A, k, l). In Figs. 3A, m-p, CAR clearly colocalized with $\mathrm{ZO}-1$, which is expressed ubiquitously in the tight junctions of collecting tubules in a kidney nephron. This shall illustrate the specificity of CAR staining in the seminiferous epithelium of the testis.

Micrographs in Fig. 3B are results of immunohistochemistry studies using testes from rats at 15 day $(a-c), 20$ day $(d-f)$, and 25 day (g-i) of age. These data support the distribution pattern of CAR seen in immunofluorescent staining. Figs. 3B $(a, d, g)$ are negative controls for each sample group, in which normal rabbit IgG was used in substitute of polyclonal rabbit anti-CAR (H-300) antibody.

A

Time of Sertoli cells in culture (day) $\left(0.5 \times 10^{6} \mathrm{cells} / \mathrm{cm}^{2}\right)$

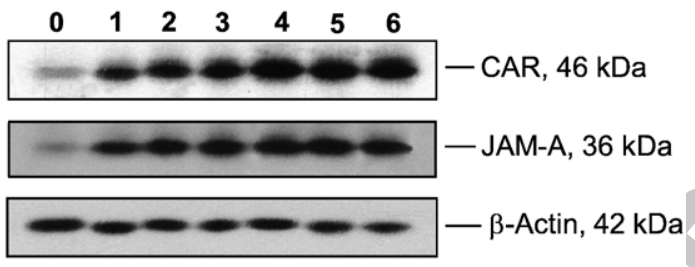

B

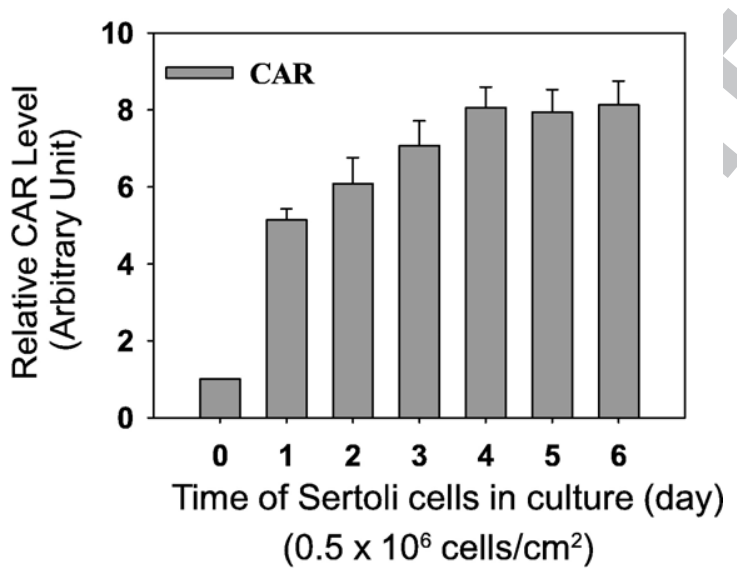

C

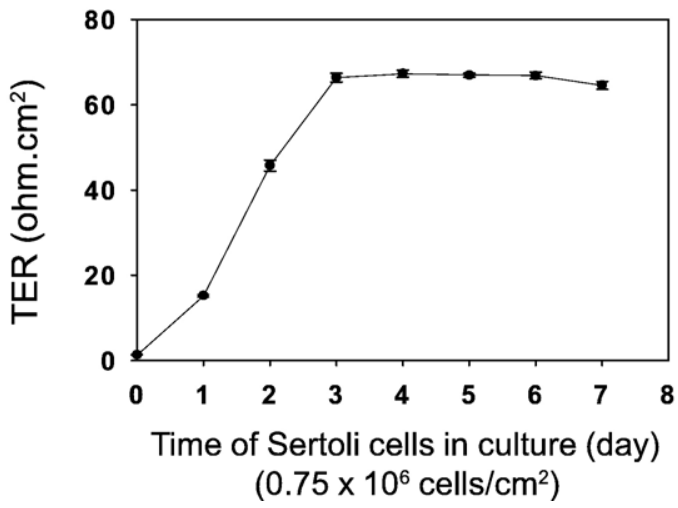

In addition, protein lysates of rat testes of different ages were analyzed by immunoblot (Fig. 3C). As shown in the bar chart (Figs. 3C, b), expression of CAR in rat testes was relatively high in neonatal rats and possibly being used to construct the blood-testis barrier at approximately 16 to 18 days of age. Overall, the CAR steady-state protein level in rat testes declined remarkably in adulthood. However, in comparison to other organs such as the brain, heart or muscle, where CAR level dropped by more than 100 -fold after maturation, the drop in CAR protein level we observed in the testes is not as drastic.

CAR is localized at inter-Sertoli cell junctions in vitro

Sertoli cells isolated from 20 -day-old rats were plated at low cell density at $0.1 \times 10^{6}$ cells $/ \mathrm{cm}^{2}$ to obtain confluent cell monolayers. Cells plated at high density often grow into an epithelium with overlapping cell layers, which would later affect the imaging of the cell-cell interface by fluorescent microscopy. Immunofluorescent staining was thus carried out after culturing Sertoli cells for 2 to 3 days (see Fig. 4 where cells were used for staining on day 3 following plating). By then, functional inter-Sertoli tight junction and adherens junctions were mostly established as shown by trans-epithelial electrical resistance measurement (TER) (Fig. 5) and electron microscopy [23]. CAR (red fluorescence) is observed to be concentrated at cell-cell contacts of Sertoli cells (Figs. 4A-B), exhibiting nearly identical localization pattern with tight junction marker ZO-1 (green fluorescence) and adherens junction protein $\mathrm{N}$-cadherin (green fluorescence).

Induction of CAR in primary Sertoli cell cultures

Sertoli cells were isolated from 20-day-old rats and were plated at $0.5 \times 10^{6}$ cells $/ \mathrm{cm}^{2}$ on Matrigel-coated dishes. At this cell density, Sertoli cells were known to form a polarized

Fig. 5 - Induction of CAR during the assembly of inter Sertoli cell junctions in vitro. Sertoli cells were cultured at high density $\left(0.5 \times 10^{6}\right.$ cells $\left./ \mathrm{cm}^{2}\right)$ for 6 days. During this time course, an intact cell epithelium with functional tight junctions and adherens junctions were established and maintained. Cell cultures were terminated at specified time points. A steady increase in CAR expression level was detected by immunoblot. JAM-A served as a protein marker of tight junction, which also has an up-regulated expression level. (A) Immunoblots illustrating changes in the protein level of CAR and JAM-A. The same blot was also probed with $\beta$-actin to confirm equal protein loading. (B) Bar graph summarizes results from 3 sets of immunoblots using different batches of Sertoli cells. The steady-state protein level of CAR in Sertoli cells at time 0 was arbitrarily set at 1, against which one-way ANOVA was performed. ${ }^{*} P<0.01$. (C) Transepithelial electrical resistance (TER) was measured at specific time points which assessed the establishment of the Sertoli cell tight junction-permeability barrier. Each time point had triplicate cultures, and each experiment was repeated 3 times using different batches of primary Sertoli cell cultures. TER reached its peak after about 4 days in culture and was maintained at that level thereafter. 
487 epithelium that mimics the morphology and cellular behavior 488 found in vivo, such as the physiological barrier maintained by 489 tight junctions. Cultures were terminated at specific time 490 points and lysed for protein extraction. As shown in Figs. 5A, B, 491 at time 0 , only a slight expression of CAR was detected by 492 immunoblots right after Sertoli cell isolation, because rigorous treatments with trypsin, collagenase and hyaluronidase in the 493 isolation process could lyse most cell adhesion proteins that 494 were used to maintain tissue organization. Expression level of 495 CAR increased rapidly (i.e., about a 5-fold boost within $24 \mathrm{~h}$ ) 496 when Sertoli cells began to create clusters, gradually form and 497 maintain an epithelium. CAR level peaked on day 4 and 498

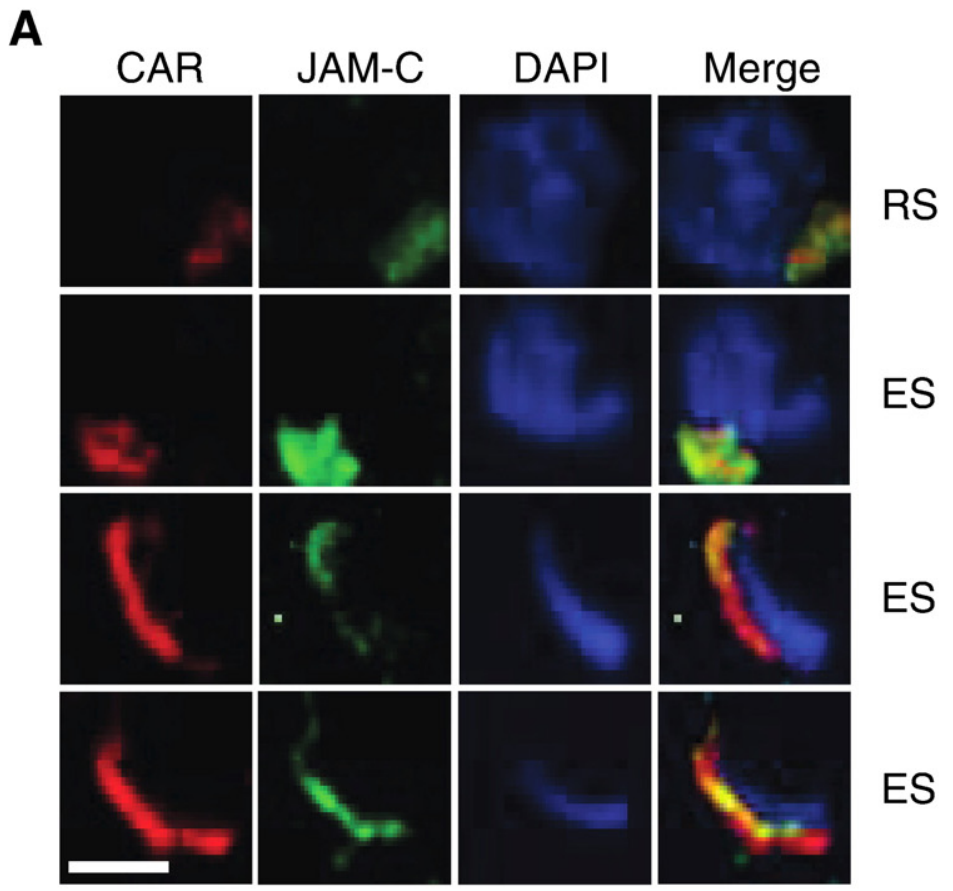

B
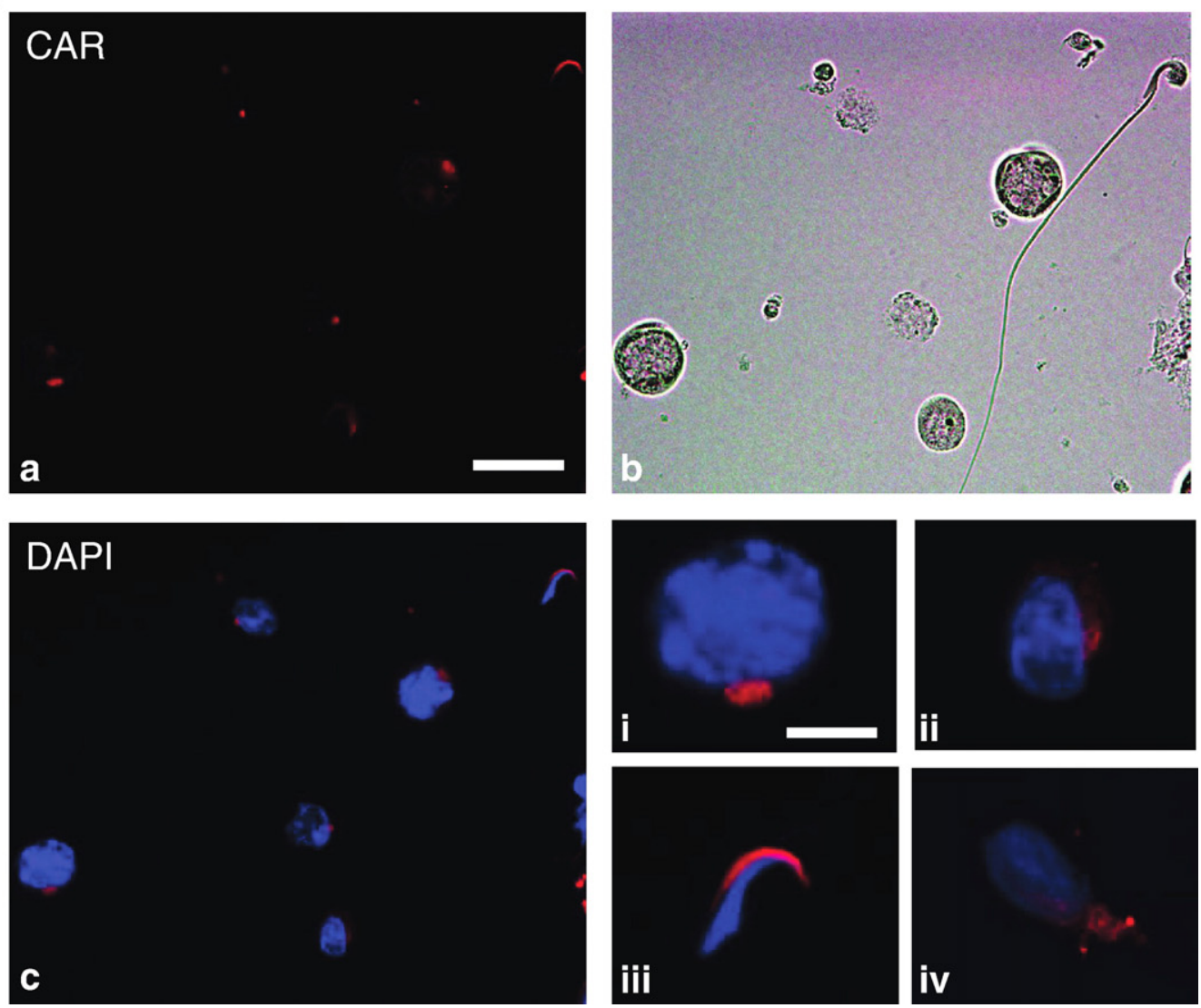

Please cite this article as: C.Q.F. Wang, et al., Coxsackie and adenovirus receptor (CAR) is a product of Sertoli and germ cells in rat testes which is localized at the Sertoli-Sertoli and Sertoli-germ..., Exp. Cell Res. (2007), doi:10.1016/j.yexcr.2007.01.017 

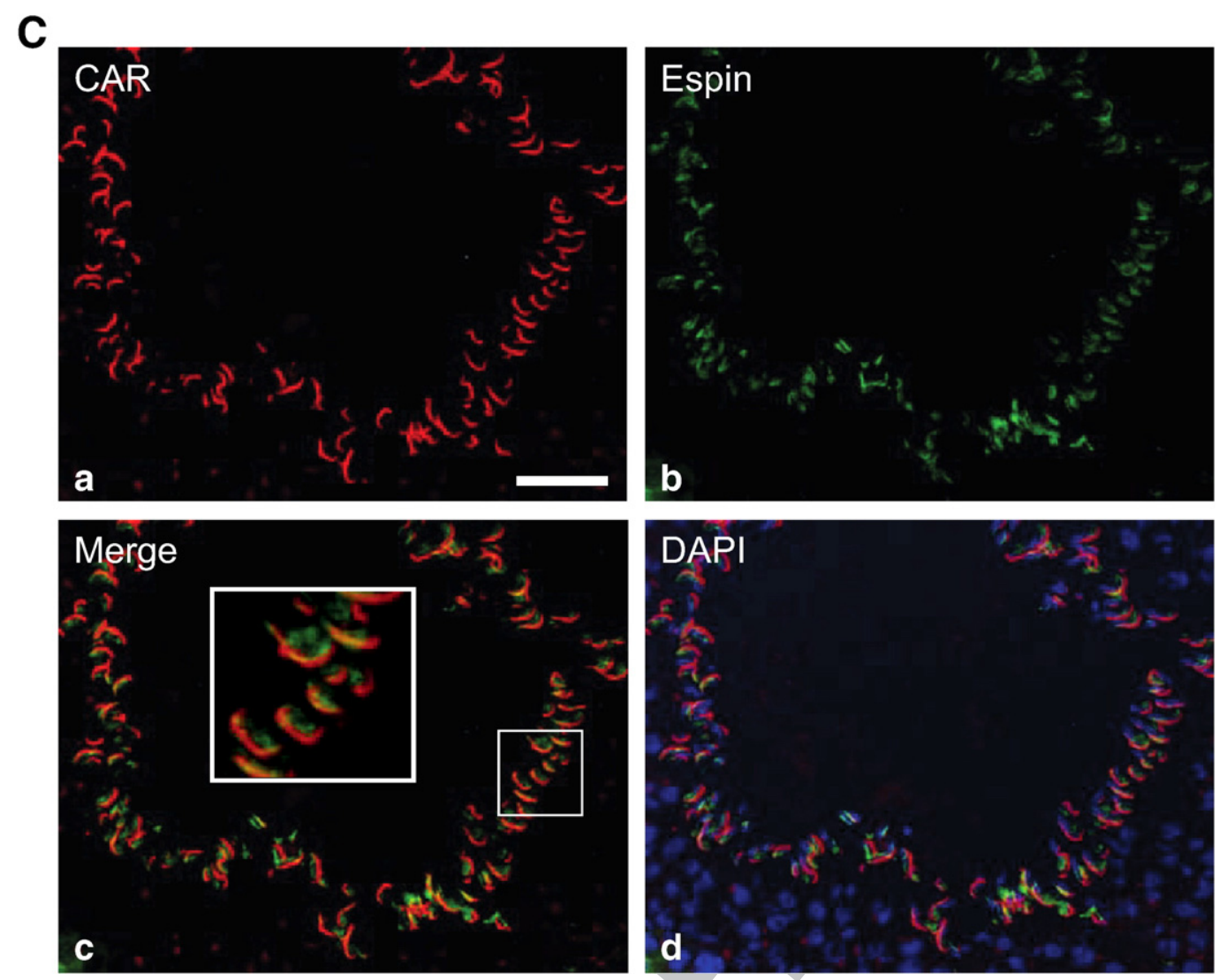

Fig. 6 - CAR is expressed by germ cells at different stages of differentiation. (A) Immunofluorescent staining of rat testes sections shows co-localization of CAR and JAM-C in vivo. Both proteins were found to be distributed on round spermatids and were confined to the heads of elongating/elongate spermatids. Scale bar $=\mathbf{5} \boldsymbol{\mu m}$. (B) Rat germ cells were isolated by mechanical procedure (without glass wool), plated on poly-L-lysine-coated coverslips and permeabilized before staining. (a) Localization of CAR on germ cells: Immunofluorescent staining was performed on the slides with rabbit anti-CAR (H-300) polyclonal antibody, followed by incubation with Cy3-conjugated donkey anti-rabbit IgG. Scale bar $=25 \mu \mathrm{m}$, which also applies to b and c. (b) Germ cells are visualized under light microscope. (c) Merged image of CAR and DAPI staining of nuclei. (i-iv) Magnified views of individual germ cells at different development stages: (i) spermatocyte, (ii) round spermatid, (iii) elongate spermatid (steps 17-18), (iv) elongating spermatid (steps 9-10). Scale bar $=5 \mu \mathrm{m}$ in (i), which also applies to (ii-iv). (C) Immunofluorescent micrographs of a stage VIII seminiferous tubule. CAR (red) was stained with a rabbit anti-CAR (H-300) polyclonal antibody and espin (green) was stained with a mouse anti-espin monoclonal antibody. Merged image (c) shows that CAR and espin were co-localized to the apical ES site in the seminiferous epithelium. Scale bar $=50 \mu \mathrm{m}$. (For interpretation of the references to colour in this figure legend, the reader is referred to the web version of this article.)

remained plateau thereafter. JAM-A, another tight junctionassociated protein, was also seen to be significantly induced during the assembly of inter-Sertoli cell junctions (Figs. 5A-B). The increase of CAR expression correlated with a rise in TER readings, which were used to assess the establishment of the inter-Sertoli cell tight junction permeability barrier (Fig. 5C). These data suggest that CAR is indeed a building block of interSertoli cell junctions at the blood-testis barrier including tight junctions and basal ectoplasmic specialization.

CAR is expressed by germ cells at different stages of differentiation

In a recent paper, CAR was found to be localized to the acrosome region of mature spermatozoa isolated from mouse epididymis and human ejaculate [18]. From our immunohistochemistry and immunofluorescent microscopy studies on rat testes sections, we noticed that CAR staining was associated with spermatogonia, spermatocytes, round spermatids as well as elongate spermatids. Immunofluorescent staining of adult rat testes sections has also co-localized CAR with JAM-C in vivo (Fig. 6A). Both proteins were found to be distributed on round spermatids and were confined to elongating/elongate spermatid heads later on. To gain a more accurate picture of CAR expression during germ cell differentiation, we conducted immunofluorescent staining with germ cells alone. The isolation process of germ cells was purely mechanical and glass wool filtration step was omitted. Therefore the final product contained germ cells at all stages of differentiation, including spermatogonia, spermatocytes, round spermatids, 
581 Sertoli cells were cultured for 4 days alone to allow the

582 formation of an epithelium with functional tight junction findings reported above (e.g., Figs. 2 and 3) represent the localization of CAR at the apical ES. In order to define the precise ultrastructural location of CAR on germ cells, immunogold electron microscopy studies were performed at the Rockefeller University Bio-imaging Resource Center. However, we encountered technical difficulties with both antibodies (Table 2). We then turned to fluorescent microscopy using double staining technique to assess the colocalization of CAR with espin at the apical ES in the seminiferous epithelium in adult rat testes (Fig. 6C). Espin is a known protein marker of ectoplasmic specialization (for a review, see [33]) contributed by Sertoli cells (Fig. 6C). Red fluorescence signals of CAR (Figs. 6C, a) appeared to Colocalize with the green fluorescence signals from espin (Figs. $6 \mathrm{C}, \mathrm{b})$ near the luminal edge of the seminiferous epithelium in a stage VIII tubule, where elongate spermatids anchored onto Sertoli cells before spermatogenesis (Figs. 6C, c, d). Due to the limited resolution of immunofluorescent imaging, data from this study are still not sufficient to distinguish between the two locations (i.e. the plasma membrane and the acrosome/acrosomal membrane). It is possible that CAR is expressed on both sites, namely the acrosome membrane and the apical ES structure. From immunohistochemistry and immunofluorescence studies on testes from 15-day-old rats, we observed that CAR staining surrounding the nuclei of spermatogonia and Sertoli cells (Figs. 3A-B). In 15-day-old rats, only spermatogonia were present in the seminiferous epithelium of pups. Considering that spermatogonia are nonpolarized stem cells without acrosome structures, significant CAR staining surrounding the nuclei of spermatogonia favors the notion that CAR is present on the plasma membrane of germ cells.

TNF $\alpha$ treatment down-regulated CAR protein level in Sertoli cell culture permeability barriers. Also the endogenous target gene expres- 583 sion pertinent to tight junction barrier assembly would have 584 subsided by then. On day 5, F12/DMEM medium containing 585 $20 \mathrm{ng} / \mathrm{mL}$ recombinant human TNF $\alpha$ were added onto these 586 cultures and cells were terminated at specified time points (see 587 Fig. 7). Medium containing the same amount of TNF $\alpha$ was 588 changed every $24 \mathrm{~h}$ afterwards. By immunoblot analysis, we 589 observed a significant drop in CAR level by days 2 and 3 after 590 TNF $\alpha$ treatment (Figs. 7A-B). However, this response to 591 cytokine treatment was not very significant in comparison to 592 that of occludin and JAM-A, which displayed a dramatic 593 decrease after only $4 \mathrm{~h}$ of treatment.

Association of CAR with other proteins examined by co-IP

For co-IP experiments, Sertoli cells were cultured alone for 596 $\sim 4$ days and terminated for lysate preparation. A rabbit 597

\section{A}

TNF $\alpha$ treatment $(20 \mathrm{ng} / \mathrm{mL})$ in Sertoli cell cultures $\left(0.5 \times 10^{6} \mathrm{cells} / \mathrm{cm}^{2}\right)$ Time after treatment

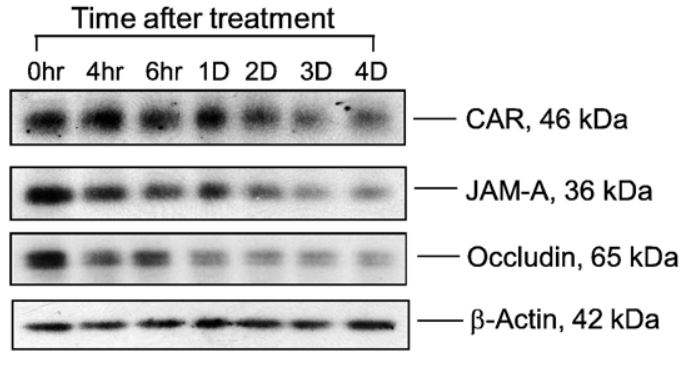

B

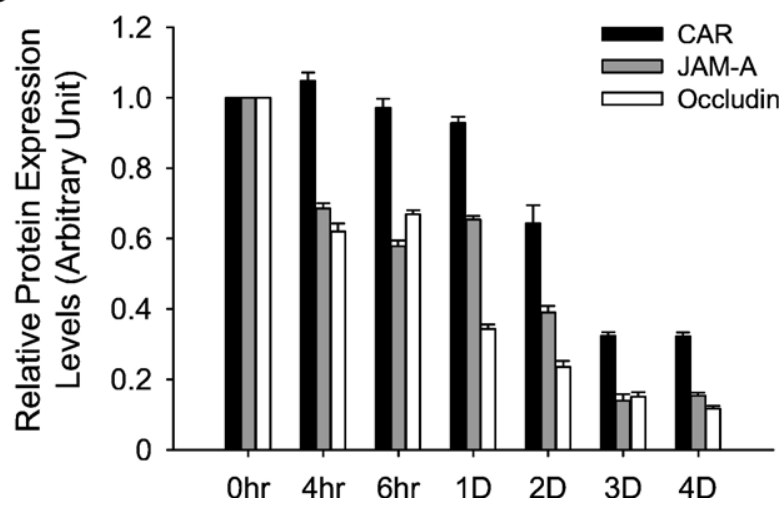

Fig. 7 - TNF $\alpha$ treatment down-regulated CAR protein level in Sertoli cell culture. Sertoli cells were cultured for $\mathbf{4}$ days prior to their use for this experiment as described in Materials and methods. Culture medium (F12/DMEM) was supplemented with TNF $\alpha(20 \mathrm{ng} / \mathrm{mL})$ on day 5 and thereafter. Cultures were terminated at specified time points and processed for immunoblot analysis. (A) CAR protein level decreased by 2 to 3 days after TNF $\alpha$ treatment, whereas the level of occludin and JAM-A dropped significantly by $4 \mathrm{~h}$ after TNF $\alpha$ treatment. (B) Bar chart summarizes results from 3 sets of immunoblot using different batches of Sertoli cell cultures. The steady-state protein level of the target protein at time 0 was arbitrarily set at 1 , against which one-way ANOVA was performed. ns, not significantly different; ${ }^{*} P<0.05$; ${ }^{* *} P<0.01$. 
598 monoclonal antibody against Src-kinase family was used as a 599 precipitating antibody to incubate with Sertoli cell lysate. 600 Immunocomplexes were separated by SDS-PAGE, transferred 601 to nitrocellulose membrane and probed with a mouse anti602 CAR antibody. Normal rabbit IgG was used in negative 603 controls. We clearly detected a band at $46 \mathrm{kDa}$ in lysates of 604 Sertoli cells that were incubated with a rabbit monoclonal 605 antibody against Src kinase family. A much stronger band of 606 the same size was identified in positive control where rabbit 607 anti-CAR (H-300) was used for precipitation (Fig. 8A). This 608 suggests that CAR was associated with members of Src kinase 609 family via direct or indirect interactions. The anti-Src antibody 610 (see Table 2) was shown to react specifically to Src as 611 illustrated in an immunoblot experiment (Fig. 8B). To further 612 verify that CAR is indeed structurally interacting with proteins 613 of Src kinase family, we next conducted immunofluorescent 614 microscopy studies on Sertoli cells in culture for 3 days at low 615 density $\left(0.1 \times 10^{6}\right.$ cells $\left./ \mathrm{cm}^{2}\right)$ to assess co-localization of CAR 616 and Src. As shown in Fig. 8C, CAR (red fluorescence) was 617 indeed co-localized with c-Src (green fluorescence), both of 618 which reside at the cell-cell interface (d vs. a-c in Fig. 8c). It is 619 possible that CAR might also co-localize with other members 620 of the Src kinase family, such as v-Src or Fyn, which we have 621 not examined in this study.

622 In order to expand the observation reported in Fig. 8A 623 regarding other binding partners for CAR, we also included 624 antibodies against other protein adaptors and kinases known 625 to affect tight and anchoring junction dynamics in Sertoli cells 626 (Figs. 8D-E). In this co-IP experiment, vinculin, and $\beta$-catenin 627 were also identified to be the putative interacting partners of 628 CAR besides Src. Fig. 8E summarizes results of this co-IP study, 629 including both positive and negative data.

\section{Discussion}

CAR is strongly expressed in multiple tissues during the embryonic and neonatal phase of rats and mice, but its level attenuated substantially in brains, hearts and became undetectable in muscles of adult animals $[3,4,7]$. The high abundance of CAR during embryonic and neonatal periods has been ascribed to its role in mediating cell adhesion during tissue morphogenesis $[4,6,7]$. In adult rat testes, extensive restructuring of cytoarchitecture occurs continuously at different stages of seminiferous epithelial cycle [13], which enables the translocation of developing germ cells from the basal to the adluminal compartment. In this respect, mature testis does undergo developmental changes which resemble those occurring in other organs during tissue genesis [30]. The persistent expression of CAR in adult rat testes indicates that it might serve an important role in spermatogenesis as a cell adhesion molecule.

Our data from cell culture experiments show that CAR resides at the inter-Sertoli cell contacts, co-localizing with tight junction marker ZO-1 as well as adherens junction protein $\mathrm{N}$-cadherin. Furthermore, we detected an induction of CAR during the formation of a functional Sertoli cell epithelium in vitro. These findings are in agreement with previous reports that CAR is an integral membrane component of tight junction or adherens junction, and potentially a homophilic adhesion molecule [7-9]. In vivo data from immunofluorescence and immunohistochemistry studies localized CAR to the site of blood-testis barrier in rats. Based on these observations, we propose that CAR is a building block of the inter-Sertoli junctions at the blood-testis barrier.

We also identified CAR expression on isolated germ cells, including spermatogonia, spermatocytes, round spermatids and elongate spermatids. Detailed description of CAR localization in spermatozoa was given in a recent paper [18]. Taken together, we concluded that CAR is constitutively expressed by germ cells during spermatogenesis, starting from spermatocytes to spermatozoa. The presence of CAR at opposing surfaces of both Sertoli and germ cells introduces the possibility that homotypical CAR interaction might take place. Structural analysis revealed that CAR form homodimer in crystal and in solution via D1 domains, the distal one of its two extracellular Ig-like loops [31]. Interestingly, fiber knob projecting from adenovirus capsid binds to CAR through the same interface, but at a higher affinity [31,32]. Viral fiber knob competes with CAR to interrupt cell-cell adhesions, not only for virus attachment [1,10], but also to spread viral particles from infected cells. To reach the airway lumen for further infection, adenovirus released at the basolateral side of the human airway epithelia must escape through adjacent cells to emerge on the apical cell surface. Viral fiber knobs facilitate this escape by competitive inhibition of CAR-CAR interactions, which either perturb junctional complex mechanically or trigger a signaling cascade to disintegrate the entire cell junction [9]. The breakthrough of viral pathogens across tissue barriers is highly reminiscent of germ cells traversing the seminiferous epithelium [13], which requires breakdown of existent inter-Sertoli junctions and instant assembly of inter Sertoli-germ adherens junctions [33]. In this scenario, CAR expressed on differentiating germ cells could interact with CAR on the Sertoli cell side, replacing the original inter-Sertoli cell CAR: CAR homodimer. During viral infection, it has been postulated that after binding with CAR, the adenovirus fiber-knob triggers a cytokine response to compromise the integrity of airway junctions [34]. It is attractive to speculate that CAR on the Sertoli cell side may have the same signaling properties to open up inter-Sertoli cell junctions, thus allowing the passage of germ cells.

Of particular interest is whether CAR presented on the Sertoli cell surface would have heterotypical interaction with JAM-C expressed on the opposing germ cell surface, since JAM$\mathrm{C}$ and CAR have been co-immunoprecipitated from mouse testes [18]. Transmembrane proteins of the immunoglobulin family have been known to confer adhesion between Sertoli and germ cells via heterotypical interactions. For example, nectin-2 and nectin-3 form heterotypical complex at the Sertoli-spermatid interface [35], and likewise JAM-B on the Sertoli cell side interact with JAM-C on spermatids in mouse testes [17]. In this study, we were not able to immunoprecipitate CAR with JAM-C using protein lysate from rat testes or Sertoli cells. This might be due to the titer or binding specificity of our antibodies. However, we did characterize the co-localization of JAM-C and CAR in rat testes at the site of apical ectoplasmic specialization, where Sertoli-spermatid junctions are present. 
In other cell types, for example, JAM-C has been observed to 717 mediate neutrophil migration through the endothelium [11].

718 Likewise, JAM-like protein on neutrophils and CAR on T84 719 monolayer were found to promote the trans-epithelial migra720 tion of neutrophils by adhesive interactions [25]. Similar 721 mechanisms could be utilized by developing preleptotene 722 spermatocytes to migrate through the tight junctions between 723 adjacent Sertoli cells, with CAR on the Sertoli cell surface 724 interacting with JAM-C on the germ cell surface. Needless to 725 say, this notion has to be vigorously investigated in future 726 studies.

727 During cytokine treatment (TNF $\alpha$ at $20 \mathrm{ng} / \mathrm{ml}$ ) of Sertoli 728 cells in culture, we observed a decline in CAR level. 729 Inflammatory cytokines, such as TNF $\alpha$, TGF $\beta$ and IFN $\gamma$, are 730 known to compromise epithelial integrity by repressing cell731 cell adhesion molecules (e.g. E-cadherin, ZO-1 and CAR) [36732 38]. Reduced expression of CAR or E-cadherin was most 733 evident among carcinomas under progression, which was 734 frequently accompanied by cytokine response in vivo $[39,40]$. 735 In the testes, TNF $\alpha$ is secreted by both Sertoli and germ cells $736[41,42]$. Our group has conducted several studies on cytokine737 mediated restructuring of the junctional complex in sperma738 togenesis [41,43-45]. We found that TNF $\alpha$ is capable of 739 perturbing Sertoli-cell tight junction barrier assembly in vitro 740 dose dependently [41]. Recently we reported that TNF $\alpha$ is also 741 a regulator of Sertoli-Sertoli and Sertoli-germ cell junctional 742 dynamics in vivo [46]. Localized production of TNF $\alpha$ from 743 Sertoli and germ cells into the microenvironment at the basal 744 compartment of seminiferous tubule may induce an "open745 ing" of inter-Sertoli cell junctions by down-regulating tight 746 junction proteins occludin and ZO-1 [46]. With this knowl747 edge, we might be able to understand the physiology of CAR 748 decrease in Sertoli cell culture after TNF $\alpha$ treatment. It is 749 notable that occludin and JAM-A responded to TNF $\alpha$ treat750 ment far more rapidly than CAR in Sertoli cell culture. After only $4 \mathrm{~h}$ of treatment, we saw a significant decline in the level of occludin and JAM-A, in comparison to the time interval of 2 to 3 days before we detected a decline in CAR level. In some types of cells, such as human airway epithelia, CAR was located within the adherens junctions at the basolateral side of the columnar cell layer, rendering the cells resistant to viral infection from the apical surface [47]. Here, it is not certain whether CAR also resides near the basal side of the Sertoli cell layers as it does in human airway epithelia. If that were the case, we might be able to explain its slow response to cytokine treatment applied from the surface of the Sertoli cell culture.

Through immunoprecipitation experiments, we identified the protein complex of CAR and Src family kinase in Sertoli cell lysate. Immunofluorescent studies did co-localize CAR with c-Src in Sertoli cell culture. The rabbit monoclonal antibody used for immunoprecipitation was targeted towards Src kinase family, so we did not assign a specific Src kinase that associated with CAR. Notably, the cytoplasmic tail of CAR does contain one putative tyrosine phosphorylation site [48]. Src kinases were known to interact with other adhesion molecules at the Sertoli-germ cell interface, including $\beta_{1}$-integrin [49] and laminin $\gamma 3$ [29]. It is conceivable that Src kinase also interacts with CAR directly or indirectly to mediate signal transduction between SertoliSertoli or Sertoli-germ cells. A recent article beautifully illustrated the mechanism of coxsackievirus invasion of tight junctions through CAR, demonstrating that Src kinase (Fyn) activation is an essential signaling event for viral internalization via caveolin-1 [50]. This poses an intriguing question of how Src kinase activity regulates germ cell movement along Sertoli cells. We also identified the interaction of CAR with vinculin and $\beta$-catenin in Sertoli cell lysates, the latter of which has already been reported as a putative binding partner of CAR in other epithelia [9]. But the

Fig. 8 - Association between CAR and different adaptors and kinases in Sertoli cells cultured in vitro. Sertoli cells were cultured for 4 days at $0.5 \times 10^{6} \mathrm{cells} / \mathrm{cm}^{2}$ that permitted the establishment of functional tight and anchoring junctions, which also mimicked the functional physiology and morphology of Sertoli cells in vivo, prior to their use for lysate preparation. (A) Co-IP experiments revealed the interaction between CAR and Src kinase in Sertoli cell lysates. $500 \mu \mathrm{g}$ of Sertoli cell lysates were prepared and immunoprecipitated with rabbit monoclonal antibody towards Src kinase family. The immunocomplexes were then subject to immunoblot analysis and incubated with a mouse anti-CAR monoclonal antibody. Rabbit anti-CAR polyclonal antibody and normal rabbit IgG were also used as precipitating antibodies for the Co-IP experiments, serving as a positive and negative control, respectively. "Rb" stands for rabbit. (B) A single prominent band corresponding to the apparent Mr of Src family protein kinase at $60 \mathrm{kDa}$ was detected on the immunoblot using Sertoli cell lysate (100 $\mu \mathrm{g}$ protein), demonstrating the specificity of the antibody. (C) Immunofluorescent staining reveals the co-localization of CAR with c-Src. Sertoli cells were cultured at low density $\left(0.1 \times 10^{6} \mathrm{cells} / \mathrm{cm}^{2}\right)$ for 3 days prior to use for fluorescent microscopy. Cells were incubated with a rabbit anti-CAR polyclonal IgG and a mouse anti-c-Src monoclonal IgG as primary antibody, followed by a donkey anti-rabbit CY3 (red fluorescence)-conjugated secondary antibody (a) and a donkey anti-mouse FITC (green fluorescence)-conjugated secondary antibody (b). Both proteins were seen to reside at cell-cell interface (a, b). Nuclei were visualized by DAPI staining (c). Areas of co-localization appear as orange (d). Scale bar $=30 \mu \mathrm{m}$ in a, which applies to b-d. (D-E) Aside from Src, we also performed co-IP studies with antibodies against other adaptors and protein kinase. In the blot shown in D, the immunocomplexes were subject to immunoblot analysis and incubated with a mouse anti-CAR monoclonal antibody. Lysates from Sertoli cells were loaded onto the same gel to illustrate the specificity of the antibody and served as positive control (+ve Ctrl). (E) Tabulated co-IP results using different antibodies against protein adaptors and kinases present in Sertoli cells. Antibodies that failed to pull down CAR were also listed here. The immunocomplexes were separated by SDS-PAGE and probed with different CAR antibodies in immunoblots. The results shown here have been repeated three times using different batches of Sertoli cell cultures. "+", positive co-IP result; “-”, negative co-IP result. (For interpretation of the references to colour in this figure legend, the reader is referred to the web version of this article.) 
direct or indirect interaction between CAR and vinculin require further investigation.

In summary, our study revealed the presence of CAR in rat Sertoli cells and its localization at intercellular junctions. We also identified CAR on isolated germ cells, including spermatogonia spermatocytes, round spermatids and elongate spermatids. The multifaceted nature of this protein was best manifested by its localization at the blood-testis barrier of the Sertoli-Sertoli cell interface as well as the apical ectoplasmic specialization at the Sertoli-germ cell interface. This suggests 795 that CAR not only serves to maintain inter-Sertoli cell 796 junctional barrier but could also be acting in concert with 797 other protein complexes to facilitate germ cell movement at 798 the Sertoli-germ cell interface. It is possible that the same 799 receptor utilized by viral pathogens to breakthrough the 800 epithelial barrier was also employed by germ cells to migrate 801 through the seminiferous epithelium during spermatogenesis. 802 Our data from immunoprecipitation and TNF $\alpha$ treatment of 803
A

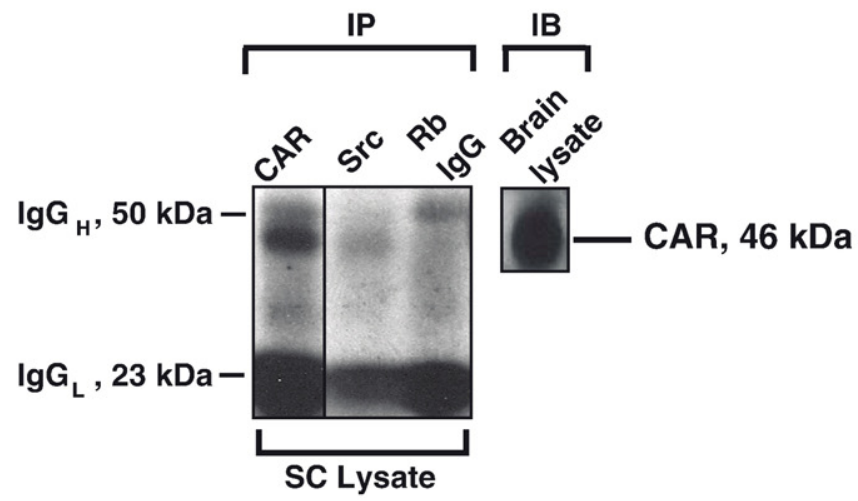

B

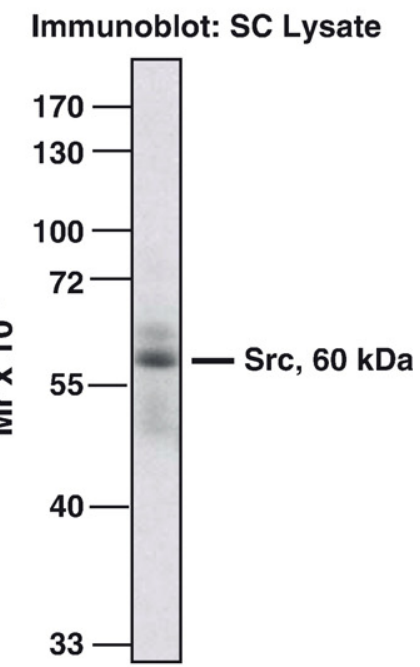

C
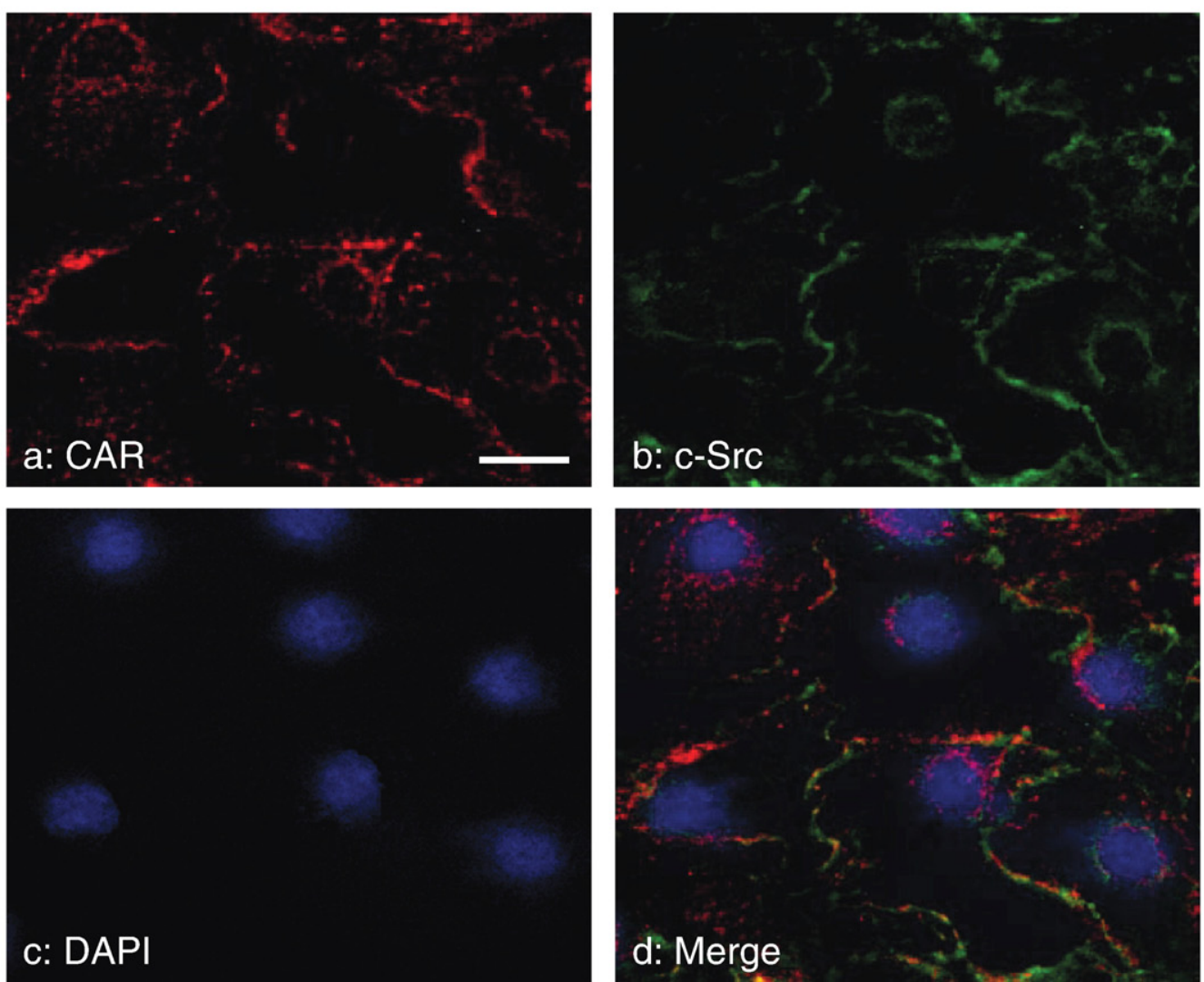

Fig. 8.

Please cite this article as: C.Q.F. Wang, et al., Coxsackie and adenovirus receptor (CAR) is a product of Sertoli and germ cells in rat testes which is localized at the Sertoli-Sertoli and Sertoli-germ..., Exp. Cell Res. (2007), doi:10.1016/j.yexcr.2007.01.017 


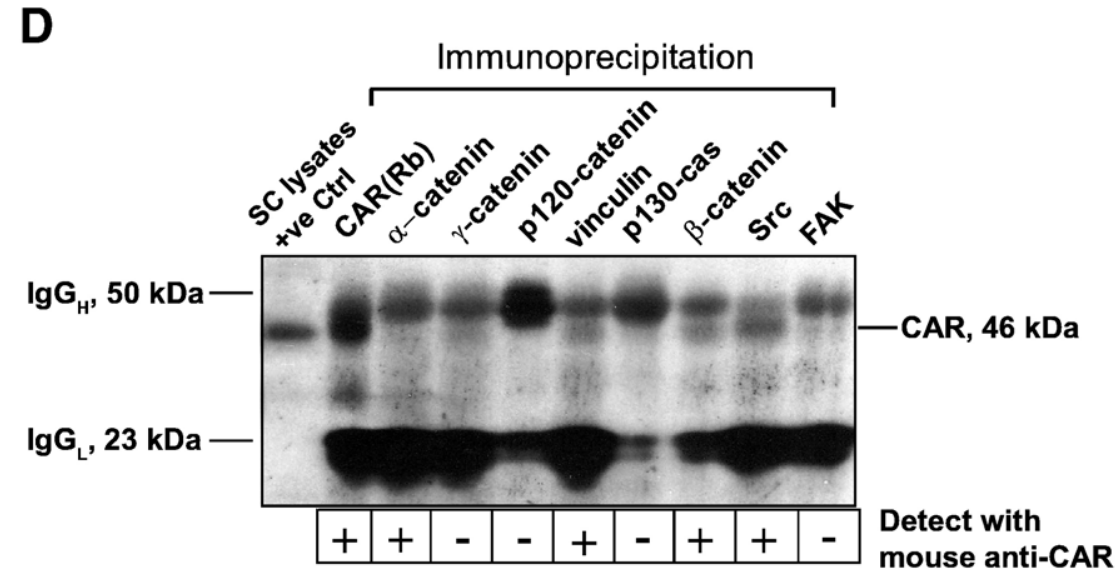

E

Association of CAR with other proteins examined by Co-IP

\begin{tabular}{|c|c|c|c|c|c|c|c|c|}
\hline & $\begin{array}{c}\text { Precipitating } \\
\text { Antibody }\end{array}$ & $\begin{array}{l}\text { Animal } \\
\text { Source }\end{array}$ & Cat. No. & Lot No. & Vendor & $\begin{array}{c}\text { IB with } \\
\text { CAR } \\
\text { (Rabbit) }\end{array}$ & $\begin{array}{c}\text { IB with } \\
\text { CAR } \\
\text { (Mouse) }\end{array}$ & $\begin{array}{c}\text { IB with } \\
\text { CAR } \\
\text { (Goat) }\end{array}$ \\
\hline \multirow{4}{*}{$\begin{array}{l}\text { Membrane } \\
\text { proteins }\end{array}$} & CAR & Rabbit & sc-15405 & $\mathrm{J} 1304$ & Santa Cruz & + & + & + \\
\hline & CAR & Mouse & sc-32795 & E2605 & Santa Cruz & + & + & - \\
\hline & CAR & Goat & sc-10313 & F0304 & Santa Cruz & - & - & - \\
\hline & $\beta 1$-integrin & Mouse & 610486 & 53855 & $\begin{array}{c}\text { BD Transduction } \\
\text { Laboratories }\end{array}$ & - & - & - \\
\hline \multirow[t]{8}{*}{ Adaptors } & $\alpha$-catenin & Rabbit & sc-7894 & A2705 & Santa Cruz & - & - & - \\
\hline & $\beta$-catenin & Rabbit & sc-7199 & F0204 & Santa Cruz & + & + & + \\
\hline & $\gamma$-catenin & Rabbit & sc-7900 & J139 & Santa Cruz & - & + & - \\
\hline & p120-catenin & Mouse & sc-23873 & D2104 & Santa Cruz & - & - & - \\
\hline & Vinculin & Rabbit & sc-5573 & I 2204 & Santa Cruz & + & + & + \\
\hline & $\alpha$-actinin & Goat & sc-7453 & D292 & Santa Cruz & - & - & - \\
\hline & p130 cas & Rabbit & 06500 & 19950 & Upstate & - & - & - \\
\hline & p-paxillin & Goat & sc-14035 & H311 & Santa Cruz & - & - & - \\
\hline \multirow[t]{3}{*}{ Kinases } & Src & Rabbit & $05-772$ & 26812 & Upstate & + & + & + \\
\hline & Pl-3 kinase & Rabbit & 06497 & 25006 & Upstate & - & + & + \\
\hline & FAK & Rabbit & sc-558 & D1806 & Santa Cruz & - & - & - \\
\hline
\end{tabular}

Fig. 8 (continued).

804 Sertoli cell cultures supports, but does not prove, the potential 805 role for CAR in promoting germ cell migration. Work is in now 806 progress to pursue this idea.

809 This work was supported in part by grants from the National 810 Institutes of Health (NICHD U01 HD045908; U54 HD29990 811 Project 3 to CYC), the CONRAD Program (CICCR, CIG 01-72 to 812 CYC), and the Hong Kong Research Grant Council (HKU 7536/ $81305 \mathrm{M}$ to WML).

\section{Appendix A. Supplementary data}

Supplementary data associated with this article can be found, 816 in the online version, at doi:10.1016/j.yexcr.2007.01.017.

REFEREN C ES

[1] J.M. Bergelson, J.A. Cunningham, G. Droguett, E.A. Kurt-Jones, A. Krithivas, J.S. Hong, M.S. Horwitz, R.L. Crowell, R.W. Finberg, Isolation of a common receptor for coxsackie B 
viruses and adenoviruses 2 and 5, Science 275 (1997) 1320-1323.

[2] J.M. Bergelson, Receptors mediating adenovirus attachment and internalization, Biochem. Pharmacol. 57 (1999) 975-979.

[3] M. Sinnreich, C.A. Shaw, G. Pari, J. Nalbantoglu, P.C. Holland, G. Karpati, Localization of coxsackie virus and adenovirus receptor (CAR) in normal and regenerating human muscle, Neuromuscul. Dis. 15 (2005) 541-548.

[4] D.R. Asher, A.M. Cerny, S.R. Weiler, J.W. Horner, M.L. Keeler, M.A. Neptune, S.N. Jones, R.T. Bronson, R.A. DePinho, W., F.R., Coxsackievirus and adenovirus receptor is essential for cardiomyocyte development, Genesis 42 (2005) 77-85.

[5] A. Nasuno, K. Toba, T. Ozawa, H. Hanawa, Y. Osman, Y. Hotta, K. Yoshida, T. Saigawa, K. Kato, R. Kuwano, Expression of coxsackievirus and adenovirus receptor in neointima of the rat carotid artery, Cardiovasc. Pathol. 13 (2004) 79-84.

[6] E. Raschperger, J. Thyberg, S. Pettersson, L. Philipson, J. Fuxe, R.F. Pettersson, The coxsackie- and adenovirus receptor (CAR) is an in vivo marker for epithelial tight junctions, with a potential role in regulating permeability and tissue homeostasis, Exp. Cell Res. 312 (2006) 1566-1580.

[7] T. Honda, H. Saitoh, M. Masuko, T. Katagiri-Abe, K. Tominaga, I. Kozakai, K. Kobayashi, T. Kumanishi, Y.G. Watanabe, S. Odani, R. Kuwano, The coxsackievirus-adenovirus receptor protein as a cell adhesion molecule in the developing mouse brain, Mol. Brain Res. 77 (2000) 19-28.

[8] C.J. Cohen, J.T.C. Shieh, R.J. Pickles, T. Okegawa, J.-T. Hsieh, J.M. Bergelson, The coxsackievirus and adenovirus receptor is a transmembrane component of the tight junction, Proc. Natl. Acad. Sci. U. S. A. 98 (2001) 15191-15196.

[9] R.W. Walters, P. Freimuth, T.O. Moninger, I. Ganske, J. Zabner, M.J. Welsh, Adenovirus fiber disrupts CAR-mediated intercellular adhesion allowing virus escape, Cell 110 (2002) 789-799.

[10] R.P. Tomko, R. Xu, L. Philipson, HCAR and MCAR: the human and mouse cellular receptors for subgroup $C$ adenoviruses and group B coxsackieviruses, Proc. Natl. Acad. Sci. U. S. A. 94 (1997) 3352-3356.

[11] T. Chavakis, T. Keiper, R. Matz-Westphal, K. Hersemeyer, U.J. Sachs, P.P. Nawroth, K.T. Preissner, S. Santoso, The junctional adhesion molecule-C promotes neutrophil transendothelial migration in vitro and in vivo, J. Biol. Chem. 279 (2004) 55602-55608.

[12] W. Ikeda, S. Kakunaga, K. Takekuni, T. Shingai, K. Satoh, K. Morimoto, M. Takeuchi, T. Imai, Y. Takai, Nectin-like molecule-5/Tage4 enhances cell migration in an integrin-dependent, nectin-3-independent manner, J. Biol. Chem. 279 (2004) 18015-18025.

[13] L. Russell, Movement of spermatocytes from the basal to the adluminal compartment of the rat testis, Am. J. Anat. 148 (1977) 313-328.

[14] C.Y. Cheng, D.D. Mruk, Cell junction dynamics in the testis: Sertoli-Germ cell interactions and male contraceptive development, Physiol. Rev. 82 (2002) 825-874.

[15] L. Russell, Observations on rat Sertoli ectoplasmic ("junctional") specializations in their association with germ cells of the rat testis, Tissue Cell 9 (1977) 475-498.

[16] S. Mueller, T.A. Rosenquist, Y. Takai, R.A. Bronson, E. Wimmer, Loss of nectin-2 at Sertoli-spermatid junctions leads to male infertility and correlates with severe spermatozoan head and midpiece malformation, impaired binding to the zona pellucida, and oocyte penetration, Biol. Reprod. 69 (2003) 1330-1340.

[17] G. Gliki, K. Ebnet, M. Aurrand-Lions, B.A. Imhof, R.H. Adams, Spermatid differentiation requires the assembly of a cell polarity complex downstream of junctional adhesion molecule-C, Nature 431 (2004) 320-324.

[18] M. Mirza, J. Hreinsson, M.-L. Strand, O. Hovatta, O. Soder, L. Philipson, R.F. Pettersson, K. Sollerbrant, Coxsackievirus and adenovirus receptor (CAR) is expressed in male germ cells and forms a complex with the differentiation factor JAM-C in mouse testis, Exp. Cell Res. 312 (2006) 817-830.

[19] I. Thoelen, C. Magnusson, S. Tagerud, C. Polacek, M. Lindberg, M. Van Ranst, Identification of alternative splice products encoded by the human coxsackie-adenovirus receptor gene, Biochem. Biophys. Res. Commun. 287 (2001) 216-222.

[20] A. Dorner, D. Xiong, K. Couch, T. Yajima, K.U. Knowlton, Alternatively spliced soluble coxsackie-adenovirus receptors inhibit coxsackievirus infection, J. Biol. Chem. 279 (2004) 18497-18503.

[21] J. Grima, L.-j. Zhu, C.Y. Cheng, Testin is tightly associated with testicular cell membrane upon its secretion by Sertoli cells whose steady-state mRNA level in the testis correlates with the turnover and integrity of inter-testicular cell junctions, J. Biol. Chem. 272 (1997) 6499-6509.

[22] M. Galdieri, E. Ziparo, F. Palombi, M.A. Russo, M. Stefanini, Pure Sertoli cell cultures: a new model for the study of somatic-germ cell interactions, J. Androl. 2 (1981) 249-254.

[23] M.K.Y. Siu, C.-h. Wong, W.M. Lee, C.Y. Cheng, Sertoli-germ cell anchoring junction dynamics in the testis are regulated by an interplay of lipid and protein kinases, J. Biol. Chem. 280 (2005) 25029-25047.

[24] G.R. Aravindan, C.P. Pineau, C.W. Bardin, C.Y. Cheng, Ability of trypsin in mimicking germ cell factors that affect Sertoli cell secretory function, J. Cell. Physiol. 168 (1996) 123-133.

[25] K. Zen, Y. Liu, I.C. McCall, T. Wu, W. Lee, B.A. Babbin, A. Nusrat, C.A. Parkos, Neutrophil migration across tight junctions is mediated by adhesive interactions between epithelial coxsackie and adenovirus receptor and a junctional adhesion molecule-like protein on neutrophils, Mol. Biol. Cell 16 (2005) 2694-2703.

[26] J. Grima, C.C.S. Wong, L.-j. Zhu, S.-d. Zong, C.Y. Cheng, Testin secreted by Sertoli cells is associated with the cell surface, and its expression correlates with the disruption of Sertoli-germ cell junctions but not the inter-Sertoli tight junction, J. Biol. Chem. 273 (1998) 21040-21053.

[27] A.H.F.M. Peters, J. Drumm, C. Ferrell, D.A. Roth, D.M. Roth, M. McCaman, P.L. Novak, J. Friedman, R. Engler, R.E. Braun, Absence of germline infection in male mice following intraventricular injection of adenovirus, Mol. Ther. 4 (2001) 603-613.

[28] M. Ito, M. Kodama, M. Masuko, M. Yamaura, K. Fuse, Y. Uesugi, S. Hirono, Y. Okura, K. Kato, Y. Hotta, T. Honda, R. Kuwano, Y. Aizawa, Expression of coxsackievirus and adenovirus receptor in hearts of rats with experimental autoimmune myocarditis, Circ. Res. 86 (2000) 275-280.

[29] R.P. Tomko, C.B. Johansson, M. Totrov, R. Abagyan, J. Frisen, L. Philipson, Expression of the adenovirus receptor and its interaction with the fiber knob, Exp. Cell Res. 255 (2000) 47-55.

[30] E.C. Roosen-Runge, In the Process of Spermatogenesis in Animals, Cambridge Univ. Press, Cambridge, U.K., 1977, pp. 1-12.

[31] M.J. van Raaij, E. Chouin, H. van der Zandt, J.M. Bergelson, S. Cusack, Dimeric structure of the coxsackievirus and adenovirus receptor D1 domain at $1.7 \AA$ resolution, Structure 8 (2000) 1147-1155.

[32] M.C. Bewley, K. Springer, Y.-B. Zhang, P. Freimuth, J.M. Flanagan, Structural analysis of the mechanism of adenovirus binding to its human cellular receptor, CAR, Science 286 (1999) 1579-1583.

[33] D.D. Mruk, C.Y. Cheng, Sertoli-Sertoli and Sertoli-germ cell interactions and their significance in germ cell movement in the seminiferous epithelium during spermatogenesis, Endocr. Rev. 25 (2004) 747-806.

[34] C.B. Coyne, J.M. Bergelson, CAR: a virus receptor within the tight junction, Adv. Drug Delivery Rev. 57 (2005) 869-882. 
[35] K. Ozaki-Kuroda, H. Nakanishi, H. Ohta, H. Tanaka, H. Kurihara, S. Mueller, K. Irie, W. Ikeda, T. Sakai, E. Wimmer, Nectin couples cell-cell adhesion and the actin scaffold at heterotypic testicular junctions, Curr. Biol. 12 (2002) 1145-1150.

[36] M.D. Lacher, M.I. Tiirikainen, E.F. Saunier, C. Christian, M. Anders, M. Oft, A. Balmain, R.J. Akhurst, W.M. Korn, Transforming growth factor-b receptor inhibition enhances adenoviral infectability of carcinoma cells via up-regulation of coxsackie and adenovirus receptor in conjunction with reversal of epithelial-mesenchymal transition, Cancer Res. 66 (2006) 1648-1657.

[37] T. Vincent, R.F. Pettersson, R.G. Crystal, P.L. Leopold, Cytokine-mediated downregulation of coxsackievirus-adenovirus receptor in endothelial cells, J. Virol. 78 (2004) 8047-8058.

[38] A. Bruning, I.B. Runnebaum, CAR is a cell-cell adhesion protein in human cancer cells and is expressionally modulated by dexamethasone, TNF $\alpha$ and TGF $\beta$, Gene Ther. 10 (2003) 198-205.

[39] A. Bruning, I.B. Runnebaum, The coxsackie adenovirus receptor inhibits cancer cell migration, Exp. Cell Res. 298 (2004) 624-631.

[40] M. Anders, C. Christian, M. McMahon, F. McCormick, W.M. Korn, Inhibition of the Raf/MEK/ERK pathway up-regulates expression of the coxsackievirus and adenovirus receptor in cancer cells, Cancer Res. 63 (2003) 2088-2095.

[41] M.K.Y. Siu, W.M. Lee, C.Y. Cheng, The interplay of collagen IV, tumor necrosis factor- $\alpha$, gelatinase B (matrix metalloprotease-9), and tissue inhibitor of metalloproteases-1 in the basal lamina regulates Sertoli cell tight junction dynamics in the rat testis, Endocrinology 144 (2003) 371-387.

[42] S.K. De, H.L. Chen, J.L. Pace, J.S. Hunt, P.F. Terranova, G.C. Enders, Expression of tumor necrosis factor- $\alpha$ in mouse spermatogenic cells, Endocrinology 133 (1993) 389-396.

[43] W.-y. Lui, W.M. Lee, C.Y. Cheng, Transforming growth factor b3 regulates the dynamics of Sertoli cell tight junctions via the p38 mitogen-activated protein kinase pathway, Biol. Reprod. 68 (2003) 1597-1612.

[44] A. Persson, X. Fan, B. Widegren, E. Englund, Cell type- and region-dependent coxsackie adenovirus receptor expression in the central nervous system, J. Neuro-Oncol. 78 (2006) 1-6.

[45] W.-Y. Lui, C.-H. Wong, D.D. Mruk, C.Y. Cheng, TGF- $\beta 3$ regulates the blood-testis barrier dynamics via the $\mathrm{p} 38$ mitogen activated protein (MAP) kinase pathway: an in vivo study, Endocrinology 144 (2003) 1139-1142.

[46] M.W.M. Li, W. Xia, D. Mruk, C.Q.F. Wang, H.H.N. Yan, M.K.Y. Siu, W.-y. Lui, W.M. Lee, C.Y. Cheng, TNF $\alpha$ can reversibly disrupt the blood-testis barrier (BTB) and impair Sertoli-germ cell adhesion - a novel mechanism to regulate junction dynamics during spermatogenesis, J. Endocrinol. 190 (2006) 315-331.

[47] R.W. Walters, T. Grunst, J.M. Bergelson, R.W. Finberg, M.J. Welsh, J. Zabner, Basolateral localization of fiber receptors limits adenovirus infection from the apical surface of airway epithelia, J. Biol. Chem. 274 (1999) 10219-10226.

[48] C.J. Cohen, J. Gaetz, T. Ohman, J.M. Bergelson, Multiple regions within the coxsackievirus and adenovirus receptor cytoplasmic domain are required for basolateral sorting, J. Biol. Chem. 276 (2001) 25392-25398.

[49] C.-H. Wong W Xia, N P.Y Lee, D D Mruk, W. L. Lee, C.Y. Cheng, Regulation of ectoplasmic specialization dynamics in 1023 the seminiferous epithelium by focal adhesion-associated 1024 proteins in testosterone-suppressed rat testes, Endocrinology 1025 146 (2005) 1192-1204.

[50] C.B. Coyne, J.M. Bergelson, Virus-induced Abl and Fyn kinase signals permit coxsackievirus entry through epithelial tight junctions, Cell 124 (2006) 119-131.

[51] Y.-L. Chan, V. Paz, J. Olvera, I.G. Wool, The primary structure of rat ribosomal protein S16, FEBS Lett. 263 (1990) $85-88$. 